\title{
Analysis of Neutron Scattering and Gamma-Ray Production Integral Experiments on Nitrogen for Neutron Energies from 1 to $15 \mathrm{MeV}$
}

S. N. Cramer

E. M. Oblow 


\section{DISCLAIMER}

This report was prepared as an account of work sponsored by an agency of the United States Government. Neither the United States Government nor any agency Thereof, nor any of their employees, makes any warranty, express or implied, or assumes any legal liability or responsibility for the accuracy, completeness, or usefulness of any information, apparatus, product, or process disclosed, or represents that its use would not infringe privately owned rights. Reference herein to any specific commercial product, process, or service by trade name, trademark, manufacturer, or otherwise does not necessarily constitute or imply its endorsement, recommendation, or favoring by the United States Government or any agency thereof. The views and opinions of authors expressed herein do not necessarily state or reflect those of the United States Government or any agency thereof. 


\section{DISCLAIMER}

Portions of this document may be illegible in electronic image products. Images are produced from the best available original document. 
Printed in the United States of America. Available from National Technical Information Service

U.S. Department of Commerce

5285 Port Royal Road, Springfield, Virginia 22161

Price: Printed Copy \$4.50; Microfiche $\$ 2.25$

This report was prepared as an account of work sponsored by the United States Government. Neither the United States nor the Energy Research and Development Administration, nor any of their employees, nor any of their contractors, subcontractors, or their employees, makes any warranty, express or implied, or assumes any legal liability or responsibility for the accuracy, completeness or usefulness of any information, apparatus, product or process disclosed, or represents that its use would not infringe privately owned rights. 
Contract No. W-7405-eng-26

Neutron Physics Division

\section{ANALYSIS OF NEUTRON SCATTERING AND GAMMA-RAY PRODUCTION \\ INTEGRAL EXPERIMENTS ON NITROGEN FOR NEUTRON ENERGIES FROM 1 TO $15 \mathrm{MeV}$}

S. N. Cramer and E. M. Oblow

NOTE

This Work Supported by DEFENSE NUCLEAR AGENCY

Under Subtask PE083

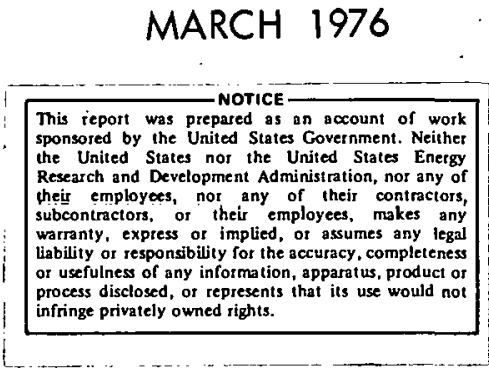

Manuscript prepared by Virginia Glidewell.

OAK RIDGE NATIONAL LABORATORY

Oak Ridge, Tennessee 37830

operated by

UNION CARBIDE CORPORATION

for the

U.S. ENERGY RESEARCH DEVELOPMENT ADMINISTRATION 
THIS PAGE

WAS INTENTIONALLY

LEFT BLANK 
Table of Contents

Page No.

Abstract - - 1

I. Introduction

II. Experimental Arrangements - 3

A. IRT Experiment -- 3

B. ORNL Experiment - 3

III. Calculational Model 4

A. Monte Carlo Codes - 4

B. Cross-Section Data and Material Specification --_--- 4

C. Calculational Procedure - 5

IV. Comparison of Experimental and Calculated Results ----- 10

V. Discussion

A. Integral Neutron Results -

B. Integral Gamma-Ray Results _-_-_-_-_- 13

C. Secondary Neutron Energy Spectra Results ---_---_-- 14

D. Gamma-Ray Secondary Spectra Results _-_-_-_-_-_-_ 15

VI. Conclusions - 16 


\section{Acknow ledgement}

The authors wish to acknowledge that the multigroup cross sections were generated by W. E. Ford as part of the AMPX project of the Computer Sciences Division. 


\section{Abstract}

Two integral experiments of, neutron scattering and gamma-ray production from nitrogen samples performed at Intelcom Radiation Technology and Oak Ridge National Laboratory were analyzed with Monte Carlo calculations. The experimental results include angular-dependent NE-213 detector count rates for both scattered neutrons and gamma-ray production from a spherical dewar of liquid nitrogen pulsed with a neutron beam with energies from 1 to $20 \mathrm{MeV}$. Additional results were reported in the ORNL experiments for unfolded scattered neutron and gamma-ray production spectra as a function of detector angle in broad incident neutron energy bins. Multigroup Monte Carlo calculations were made to analyze all the reported results. Conclusions were drawn about the status of the ENDF/B-IV nitrogen cross-section data file from the comparison of calculated and experimental results. 


\section{Introduction}

Calculations of neutron and gamma-ray integral count rates and secondary energy spectra have been performed for comparison with integral experiments on liquid nitrogen. The experiments conducted at Intelcom Radiation Technology ${ }^{l}$ and Oak Ridge National Laboratory, ${ }^{2}$ and the calculational analysis are part of the Defense Nuclear Agency data testing program designed to test neutron scattering and gamma-ray production data for several nuclides of interest for incident neutron energies from 1 to $15 \mathrm{MeV}$. The calculations, experiments, and comparisons presented here are similar to those previously performed for carbon. ${ }^{3}$ In the earlier report ${ }^{3}$ the procedures for the data testing program were outlined in terms of experimental techniques, calculational models, and methods of data comparison.

In both the IRT and ORNL experiments a collimated beam of neutrons traveling approximately 50 meters impinged on a target consisting of a dewar filled with liquid nitrogen. NE-213 spectrometers were used to detect both neutrons and gamma rays scattering from the target. The detectors were placed out of the line-of-sight of the incident neutron beam at angles of approximately 30, 55, 90, and $125 \mathrm{deg}$ with respect to the direction of the incident beam. The scattering data were reduced to neutron and gamma-ray counts as a function of time and reported as counts per incident neutron as a function of incident neutron energy by using time-of-flight considerations. Pulse-height information was also recorded as a function of arrival time so that the differential spectrum of scattered neutrons and gamma rays could be obtained by unfolding techniques as a function of incident neutron energy. The experimental data are reported in Refs. 1 and 2 .

Analysis of both experiments was based on calculations made with the MORSE $^{4}$ multigroup Monte Carlo code using coupled neutron and gamma-ray. multigroup data processed by the $\mathrm{AMPX}^{5}$ code system. The data set used was ENDF/B-IV nitrogem MAT 1275 (DNA MAT 4133 Mod 4). The results presented contain not only the comparisons of the experiment, with the calculations but also sensitivity studies of the effect of the dewar on the calculations and the importance of first-scattered neutrons. 
The experimental arrangements are described in Section II and the calculational models in Section III. Experimental and calculational results are presented in Section IV followed by a discussion in Section V. Conclusions concerning the current status of the nitrogen data files are drawn in Section VI.

\section{Experimental Arrangements}

\section{A. IRT Experiment}

The IRT LINAC was used to create a white pulsed neutron source (50 nsec burst width) with a Be target. These neutrons traversed a 53-meter flight path to the nitrogen sample as shown in Fig. 1. The scattering sample was a styrofoam dewar filled with liquid nitrogen, shown schematically in Fig. 2. The four placements of the NE-213 detector, used for both neutron and gamma-ray detection, are shown in Fig. 3. Data were reported as neutron and gamma-ray counts per incident neutron per $\mathrm{cm}^{2}$ of sample cross-sectional area as a function of the incident neutron energy. Secondary energy spectra were also recorded for the neutrons at the 125deg detector position. 6

\section{B. ORNL Experiment}

The ORNL experimental arrangement was similar to the one used at IRT. The Oak Ridge Electron Linear Accelerator (ORELA) was used to create a white pulsed neutron source (12 nsec burst width) from $\mathrm{Be}(\gamma, \mathbf{n})$ target interactions. These neutrons were collimated into a beam with an effective diameter of $13.26 \mathrm{~cm}$ which traveled 47.35 meters along a flight path to the scattering sample. The pulsed source produced a uniformly distributed monodirectional source at the position of the nitrogen sample.

The scattering sample consisted of a thin evacuated Pyrex dewar filled with 4.27 liters of liquid nitrogen with a density of $0.81 \mathrm{~g} / \mathrm{cm}^{3}$. The dewar weighed 1256.5 grams and was $22.69 \mathrm{~cm}$ In diameter. Complete specifications of the dewar are given in Fig. 4 and In Ref. 2. The 
$4.22 \mathrm{~cm} \times 4.65 \mathrm{~cm} \mathrm{NE}-213$ detector; used for both neutron and gamma-ray detection, was placed at four different positions corresponding to angles of $30,55,90$, and $125 \mathrm{deg}$ with respect to the incident neutron beam direction. The collimated beam was centered on the face of the dewar at an angle of 2 deg with respect to the horizontal line of the detectors. The experimental data consisted of integral count rates and energydependent spectra for both neutrons and gamma rays at each detector position.

\section{Calculational Model}

\section{A. Monte Carlo Codes}

All calculations presented in this report were made with the MORSE multigroup Monte Carlo code using a coupled neutron-gamma multigroup crosssection data library processed by the AMPX code system. As a check on all neutron count-rate calculations, the $06 \mathrm{R}^{7}$ point-energy Monte Carlo code was also used. Since comparisons of all results produced by both MORSE and $06 \mathrm{R}$ were consistent, only the MORSE results are presented.

\section{B. Cross-Section Data and Material Specification}

The nitrogen cross sections used in the calculations were based on the DNA MAT 4133 Mod 4 nitrogen data file (equivalent to ENDF/B-IV). The nitrogen density in the sample was taken to be $0.034 /$ atom/barn em for the IRT experiment and 0.0348 atom/barn-cm for the ORNL arrangement. To model the IRT styrofoam dewar DNA MAT 4274 Mod 0 and.DNA MAT 4148 Mod 2 were used for the carbon and hydrogen, respectively. The density of each was taken to be 0.00138 atom/barn-cm. The ORNL Pyrex dewar was assumed to be pure $\mathrm{SiO}_{2}$ and DNA MAT 4151 Mod 3 and DNA MAT 4134 Mod 2 data were used for the silicon and oxygen, respectively. A density of 0.00775 atom/barn-cm was used for the silicon and 0.0155 atom/barn-cm for oxygen.

The cross sections for each case were processed by AMPX into a 10123 coupled neutron-gamma group structure with a $1 / E$ welghting function to simulate the incident source neutron spectrum and a $\mathrm{P}_{7}$ Legendre expansion. 
The cross-section group structure is shown in Table I. An equal lethargy grid between $20 \mathrm{MeV}$ and $300 \mathrm{keV}$ was chosen for the neutrons and the gammaray group structure was hand picked to cover the important gamma-ray production regions from $11 \mathrm{MeV}$ to $400 \mathrm{keV}$.

\section{Calculational Procedure}

Neutrons and gamma rays were followed from production to detection as a function of space, angle, and time. Neutron histories were started uniformly per unit lethargy from $20 \mathrm{MeV}$ to the lowest energy with reported experimental data. The initial spatial coordinates of the neutrons were determined by selecting $x$ and $y$ uniformly over the effective crosssectional area of the neutron beam $\left(138.1 \mathrm{~cm}^{2}\right.$ for ORNL and $373.25 \mathrm{~cm}^{2}$ for IRT) and placing $z$ at the leading edge of the sample. Neutrons were started straight ahead in the $z$ direction. Gamma rays produced in the sample acquired the position, time, and calculational weight of the neutrons which produced them.

Source neutrons in each energy group were given initial times determined by the neutron time-of-flight of a neutron at the midpoint of each energy group to the leading edge of the sample. Relativistic velocities were used throughout the calculations. The initial times were smeared with a Gaussian approximation of the experimentally determined time spread as follows :

$$
\Delta t=(R 1-R 2) \times T
$$

where $R 1$ and $R 2$ are random numbers and $T=50 \mathrm{nsec}$ for the IRT experiment and $\mathrm{T}=12 \mathrm{nsec}$ for the ORNL experiment.

The ralculational set up for the IRT experiment was taken from Figs. 1, 2, and 3. The filler tube was extended $50 \mathrm{~cm}$ above the dewar. The reservoir, floor, and air were neglected. The calculational model for the ORNL experiment is shown in Figs. 4 and 5. The fill tube was excluded from the modelling of the Pyrex dewar. 
Table I. Energy Structure (141 Neutron Groups and Gamma-Ray Groups) and Detector Efficiencies

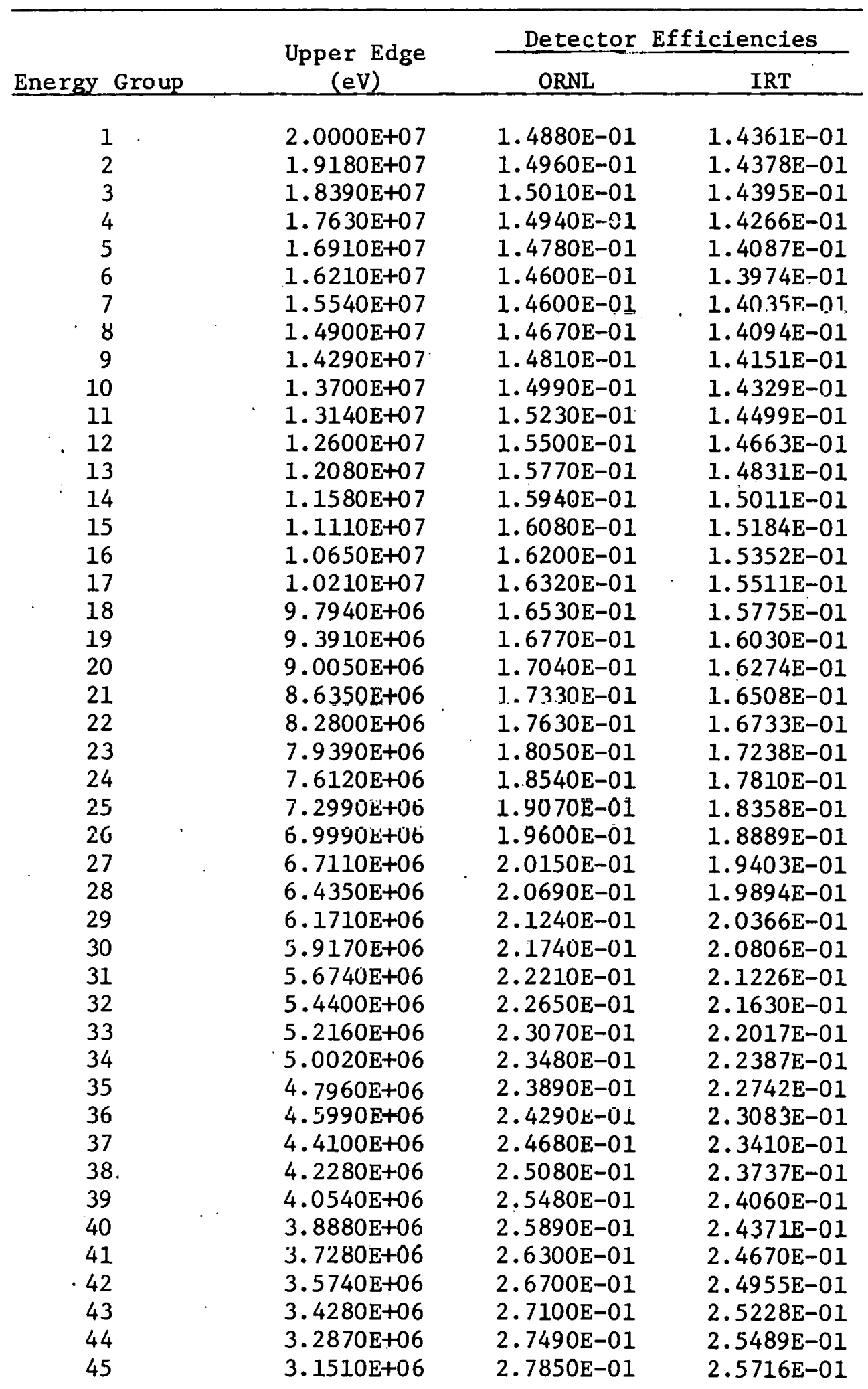


Table I (Cont'd.)

\begin{tabular}{|c|c|c|c|}
\hline \multirow[b]{2}{*}{ Energy Group } & \multirow{2}{*}{$\begin{array}{c}\text { Upper Edge } \\
(\mathrm{eV})\end{array}$} & \multicolumn{2}{|c|}{ Detector Efficiencies } \\
\hline & & ORNL & IRT \\
\hline 46 & $3.0220 \mathrm{E}+06$ & $2.8210 \mathrm{E}-01$ & $2.5932 \mathrm{E}-01$ \\
\hline 47 & $2.8980 \mathrm{E}+06$ & $2.8550 \mathrm{E}-01$ & $2.6141 \mathrm{E}-01$ \\
\hline 48 & $2.7780 \mathrm{E}+06$ & $2.8890 \mathrm{E}-01$ & $2.6342 \mathrm{E}-01$ \\
\hline 49 & $2.6640 E+06$ & $2.9210 \mathrm{E}-01$ & $2.6534 \mathrm{E}-01$ \\
\hline 50 & $2.5540 \mathrm{E}+06$ & $2.9520 \mathrm{E}-01$ & $2.6718 \mathrm{E}-01$ \\
\hline 51 & $2.4490 E+06$ & $2.9830 \mathrm{E}-01$ & $2.6894 \mathrm{E}-01$ \\
\hline 52 & $2.3480 E+06$ & $3.0120 \mathrm{E}-01$ & $2.7063 \mathrm{E}-01$ \\
\hline 53 & $2.2520 \mathrm{E}-06$ & $3.0390 \mathrm{E}-01$ & $2.7146 \mathrm{E}-01$ \\
\hline 54 & $2.1600 \mathrm{E}+06$ & $3.0620 \mathrm{E}-01$ & $2.7037 \mathrm{E}-01$ \\
\hline 55 & $2.0710 \mathrm{E}+06$ & $3.0840 \mathrm{E}-01$ & $2.6933 \mathrm{E}-01$ \\
\hline 56 & $1.9860 E+06$ & $3.1050 \mathrm{E}-01$ & $2.6833 \mathrm{E}-01$ \\
\hline 57 & $1.99040 \mathrm{E}+06$ & 3. $1250 \mathrm{E}-01$ & $2.6737 \mathrm{E}-01$ \\
\hline 58 & $1.8260 \mathrm{E}+06$ & $3.1430 \mathrm{E}-01$ & $2.6645 \mathrm{E}-01$ \\
\hline 59 & 1. $7500 \mathrm{E}+06$ & 3. $1600 \mathrm{E}-01$ & $2.6556 \mathrm{E}-01$ \\
\hline 60 & $1.6780 \mathrm{E}+06$ & $3.1770 \mathrm{E}-01$ & $2.6472 \mathrm{E}-01$ \\
\hline 61 & $1.6090 \mathrm{E}+06$ & 3. $1850 \mathrm{E}-01$ & $2.6067 \mathrm{E}-01$ \\
\hline 62 & $1.5430 \mathrm{E}+06$ & $3.1860 \mathrm{E}-01$ & $2.5426 \mathrm{E}-01$ \\
\hline 63 & 1. $4800 \mathrm{E}+06$ & $3.1830 \mathrm{E}-01$ & $2.4809 E-01$ \\
\hline 64 & $1.4190 \mathrm{E}+06$ & $3.1790 \mathrm{E}-01$ & $2.4213 \mathrm{E}-01$ \\
\hline 65 & 1. $3600 \mathrm{E}+06$ & $3.1730 \mathrm{E}-01$ & $2.3646 \mathrm{E}-01$ \\
\hline 66 & $1.3050 \mathrm{E}+06$ & $3.1650 \mathrm{E}-01$ & $2.3104 \mathrm{E}-01$ \\
\hline 67 & $1.2510 \mathrm{E}+06$ & $3.1560 \mathrm{E}-01$ & $2.2582 \mathrm{E}-01$ \\
\hline 68 & $1.2000 E+06$ & $3.1210 \mathrm{E}-01$ & $2.1145 \mathrm{E}-01$ \\
\hline 69 & 1. $1500 \mathrm{E}+06$ & $3.0640 E-01$ & $1.9151 \mathrm{E}-01$ \\
\hline 70 & $1.1030 \mathrm{E}+06$ & $3.0010 \mathrm{E}-01$ & 1. $7260 \mathrm{E}-01$ \\
\hline 71 & $1.0580 E+06$ & $2.9310 \mathrm{E}-01$ & $1.5431 \mathrm{E}-01$ \\
\hline 72 & $1.0140 \mathrm{E}+06$ & $2.8550 E-01$ & 1. $3670 \mathrm{E}-01$ \\
\hline 73 & $9.7230 \mathrm{E}+05$ & $2.7760 \mathrm{E}-01$ & 1. $1990 \mathrm{E}-01$ \\
\hline 74 & $9.3230 E+05$ & $2.6910 E-01$ & $1.0381 E-01$ \\
\hline 7.5 & $8.9400 E+05$ & $2.5530 E-01$ & $9.0175 \mathrm{E}-02$ \\
\hline 76 & $8.5720 E+05$ & $2.3820 \mathrm{E}-01$ & $7.7658 \mathrm{E}-02$ \\
\hline 77 & $8.2200 E+05$ & $2.2000 \mathrm{E}-01$ & $6.5662 \mathrm{E}-02$ \\
\hline 78 & $7.8820 E+05$ & $2.0070 \mathrm{E}-01$ & $5.4136 \mathrm{E}-02$ \\
\hline 79 & $7.5570 \mathrm{E}+05$ & $1.8050 \mathrm{E}-01$ & $4.3097 \mathrm{E}-02$ \\
\hline 80 & $7.2470 E+05$ & $1.5970 \mathrm{E}-01$ & $3.2527 \mathrm{E}-02$ \\
\hline 81 & $6.9490 E+05$ & 1. $3830 \mathrm{E}-01$ & $2.2374 E-02$ \\
\hline 82 & $6.6630 \mathrm{E}+05$ & $1.1660 \mathrm{E}-01$ & $1.2638 \mathrm{E}-02$ \\
\hline 83 & $6.3890 E+05$ & $9.4650 \mathrm{E}-02$ & 3. $3024 \mathrm{E}-03$ \\
\hline 84 & $6.1260 E+05$ & $7.8380 \mathrm{E}-02$ & $0.0000 \mathrm{E}-00$ \\
\hline 85 & $5.8740 E+05$ & $6.6010 \mathrm{E}-02$ & $0.0000 \mathrm{E}-00$ \\
\hline 86 & $5.6320 \mathrm{E}+05$ & $5.4590 \mathrm{E}-02$ & $0.0000 \mathrm{E}-00$ \\
\hline 87 & 5. 4010E+05 & $4.4040 E-02$ & $0.0000 \mathrm{E}-00$ \\
\hline 88 & $5.1790 E+05$ & $3.4260 \mathrm{E}-02$ & $0.0000 E-00$ \\
\hline 89 & $4.9660 \mathrm{E}+05$ & $2.5220 \mathrm{E}-02$ & $0.0000 \mathrm{E}-00$ \\
\hline 90 & $4.7620 E+05$ & $1.6840 \mathrm{E}-02$ & $0.0000 E-00$ \\
\hline
\end{tabular}


Table I (Cont'd.)

\begin{tabular}{|c|c|c|c|}
\hline \multirow[b]{2}{*}{ Energy Group } & \multirow{2}{*}{$\begin{array}{c}\text { Upper Edge } \\
(\mathrm{eV})\end{array}$} & \multicolumn{2}{|c|}{ Detector Efficiencies } \\
\hline & & ORNL & IRT \\
\hline 91 & $4.5660 E+05$ & $9.0800 \mathrm{E}-03$ & $0.0000 \mathrm{E}-00$ \\
\hline 92 & $4.3780 \mathrm{E}+05$ & $2.2110 \mathrm{E}-03$ & $0.0000 \mathrm{E}-00$ \\
\hline 93 & 4. $1980 \mathrm{E}+05$ & $3.0470 E-06$ & $0.0000 E-00$ \\
\hline 94 & $4.0250 \mathrm{E}+05$ & $0.0000 \mathrm{E}-00$ & $0.0000 \mathrm{E}-00$ \\
\hline 95 & $3.8600 \mathrm{E}+05$ & $0.0000 E-00$ & $0.0000 E-00$ \\
\hline 96 & 3. $7010 \mathrm{E}+05$ & $0.0000 E-00$ & $0.0000 E-00$ \\
\hline 97 & $3.5490 \mathrm{E}+05$ & $0.0000 \mathrm{E}-00$ & $0.0000 \mathrm{E}-00$ \\
\hline 98 & $3.4030 \mathrm{E}+05$ & $0.0000 \mathrm{E}-00$ & $0.0000 E-00$ \\
\hline 99 & $3.2630 \mathrm{E}+05$ & $0.0000 \mathrm{E}-00$ & $0.0000 \mathrm{E}-00$ \\
\hline 100 & $3.1290 \mathrm{E}+05$ & $0.0000 \mathrm{E}-00$ & $0.0000 E-00$ \\
\hline 101 & $3.0000 \mathrm{E}+05$ & $0.0000 \mathrm{E}-00$ & $0.0000 \mathrm{E}-00$ \\
\hline $10 \overline{2}$ & 1. $1000 \mathrm{E}+07$ & $1.7946 \mathrm{E}-02$ & $1.5800 \mathrm{E}-01$ \\
\hline 103 & $1.0000 \mathrm{E}+07$ & $1.6781 \mathrm{E}-02$ & $1.6000 \mathrm{E}-01$ \\
\hline 104 & $9.0000 \mathrm{E}+06$ & $1.5574 \mathrm{E}-02$ & $1.6200 \mathrm{E}-01$ \\
\hline 105 & $8.0000 E+06$ & $1.4672 \mathrm{E}-02$ & $1.6325 \mathrm{E}-01$ \\
\hline 106 & $7.5000 E+06$ & $1.3917 \mathrm{E}-02$ & $1.6390 \mathrm{E}-01$ \\
\hline 107 & $6.7000 E+06$ & $1.3175 \mathrm{E}-01$ & $1.6455 \mathrm{E}-01$ \\
\hline 108 & $6.2000 E+06$ & $1.2753 \mathrm{E}-01$ & $1.6500 \mathrm{E}-01$ \\
\hline 109 & $5.8000 \mathrm{E}+06$ & $1.2573 \mathrm{E}-01$ & $1.6660 \mathrm{E}-01$ \\
\hline 110 & $5.4000 \mathrm{E}+06$ & $1.2387 \mathrm{E}-01$ & $1.6820 \mathrm{E}-01$ \\
\hline 111 & $5.0000 \mathrm{E}+06$ & $1.2185 \mathrm{E}-01$ & $1.6960 \mathrm{E}-01$ \\
\hline 112 & $4.6000 E+06$ & $1.1969 \mathrm{E}-0.1$ & $1.7080 \mathrm{E}-01$ \\
\hline 113 & 4. $2000 E+06$ & $1.1793 \mathrm{E}-01$ & 1. $7200 \mathrm{E}-01$ \\
\hline 114 & $3.8000 E+06$ & $1.1601 \mathrm{E}-01$ & $1.7320 \mathrm{E}-01$ \\
\hline 115 & $3.4000 \mathrm{E}+06$ & $1.1372 \mathrm{E}-01$ & $1.7440 \mathrm{E}-01$ \\
\hline 116 & $3.0000 \mathrm{E}+06$ & 1. $1095 \mathrm{E}-01$ & 1. $7650 \mathrm{E}-01$ \\
\hline 117 & $2.5000 \mathrm{E}+06$ & $1.0804 \mathrm{E}-01$ & $1.7950 \mathrm{E}-01$ \\
\hline 118 & $2.0000 E+06$ & $1.0130 \mathrm{E}-01$ & $1.8300 \mathrm{E}-01$ \\
\hline 119 & 1. $5000 \mathrm{E}+06$ & $8.3328 \mathrm{E}-01$ & $1.8500 \mathrm{E}-01$ \\
\hline 120 & $1.0000 E+06$ & $3.9669 \mathrm{E}-02$ & $1.8300 \mathrm{E}-01$ \\
\hline 121 & $8.0000 E+05$ & $2.4652 \mathrm{E}-02$ & $1.7200 \mathrm{E}-01$ \\
\hline 122 & $6.0000 \mathrm{E}+05$ & $0.0000 E-00$ & $1.4700 \mathrm{E}-01$ \\
\hline 123 & $4.0000 E+05$ & $0.0000 \mathrm{E}-00$ & $1.0000 \mathrm{E}-00$ \\
\hline
\end{tabular}


Count rates were calculated as $\phi \times \varepsilon \times A$ where $\phi$ is the flux at the detector center determined by next flight estimation, $\varepsilon$ is the detector efficiency given in Table $I$, and $A$ is the detector cross-sectional area, $21.4 \mathrm{~cm}^{2}$ for IRT and $19.6 \mathrm{~cm}^{2}$ for ORNL. The count rates were converted to counts per incident source neutron per $\mathrm{cm}^{2}$ by multiplying the count rate by the time bin width and dividing by the corresponding energy group width in MeV. The fraction of incident neutrons in each energy group was equal (within statistics) since the group boundaries were equally spaced in lethargy and the starting energies were selected uniformly in lethargy.

The detector count rates were reported as functions of the incident neutron energy, E, determined from time-of-flight considerations as follows:

$$
\mathrm{T}=\frac{\mathrm{D}}{\sqrt{1-\frac{1}{\left(1+\frac{E^{\prime}}{2 c^{2}}\right)^{2}}}}
$$

where

$$
\begin{aligned}
T= & \text { flight time in sec from accelerator source to sample face for } \\
& \text { a neutron of energy } E \text { at the source, } \\
D= & \text { distance in } \mathrm{cm} \text { from accelerator source to sample face, } \\
E^{\prime}= & 1.91322 \times 10^{12} \times \mathrm{E} \text {, where } \mathrm{E} \text { is the energy in } \mathrm{MeV}, \\
\mathrm{C}= & \text { speed of light in } \mathrm{cm} / \mathrm{sec} \text {. }
\end{aligned}
$$

Although the flight times of the neutrons in the sample and to the detector were included in the calculations, they were generally negligible compared to the flight time from the source to the sample as determined in Eq. (2).

Gamma-ray counts induced in the IRT detector by neutrons inelastically scattering from the detector materials were included in the calculated results. This was done by multiplying the neutron flux at the detector by an appropriate energy-dependent detector gamma-ray production function provided by the experimentalist (similar in form to $\varepsilon$ ) and adding this to the 
gamma-ray count rates arising from the gammas produced in the sample. In the ORNL experiment, the neutron-induced gamma-ray counts were removed from the original experimental data by the experimentalists.

The calculated secondary energy spectra for the ORNL experiment included an empirically determined energy resolution function for the detector given by $R$, the FWHM in percent:

$$
R=\sqrt{A+B / E}
$$

where A was 250 for neutrons and 170 for gamma rays; B was 670 for neutrons and 288 for gamma rays; and $\mathrm{E}$ is an energy in $\mathrm{MeV}$ uniformly selected in the energy group of the detected particle. The energy resolution function for the IRT spectra calculations was provided by the experimentalist in tabulated form. The spectra were obtained by time-dependent calculations with time bins being determined by Eq. (2) with E corresponding to the broad incident neutron energy boundaries used in unfolding the experimental spectra.

\section{Comparison of Experimental and Calculated Results}

The figures which follow summarize the calculations performed for all experimentally determined data for the two experiments. Integral countrate comparisons for both neutrons and gamma rays for the IRT experiments are given in Figs. 6 through 9. The corresponding results for the ORNL experiment are shown in Figs. 10 through 13. In all figures the experimental and calculational error bars represent one standard deviation from the mean value.

The only secondary energy spectra results reported for the IRT experiment were for neutrons at the $125-\mathrm{deg}$ detector position. Calculational analysis of these results are shown in Figs. 14, 15, and 16. Figures 17 through 40 give the ORNL secondary energy spectra comparisons for both neutrons and gamma rays for all four detector angles. In all the multiple energy spectra figures, each set of comparisons is plotted at the midpoint of the appropriate incident neutron energy bin (e.g., the plots at 
11. $25 \mathrm{MeV}$ on the slanted energy scale correspond to the secondary spectra resulting from the scattering of incident neutrons in the 10.0-12.5 MeV energy range by the nitrogen sample).

In addition to the regular comparisons of the calculated and experimental results, sensitivity runs were made for the IRT experiment to see what effect water or ice condensation on the outside of the dewar would have on the calculated results. Figures 41 through 44 show typical results for these cases. A fuller discussion of this effect appears in the discussion to follow.

\section{Discussion}

\section{A. Integral Neutron Results}

The analysis of both the ORNL and IRT integral neutron count results at 90 and $125 \mathrm{deg}$ yielded the best consistant agreement between calculated and experimental results (see Figs. 9 and 13). Significant discrepancies of the order of $30 \%$ do appear in the comparison at $125 \mathrm{deg}$ for neutron energies above $10 \mathrm{MeV}$ with the calculations being consistantly high. This high energy discrepancy is less pronounced at $90 \mathrm{deg}$ but the 3 to $6 \mathrm{MeV}$ range begins to show consistant disagreements at this detector angle (see Figs. 8 and 12).

At the two forward detector positions of 30 and $55 \mathrm{deg}$ the disagreement between the calculations and the measurements becomes more significant (see Figs. 6, 7, 10, and 11). More disturbing, however, is the inconsistancy exhibited in the comparison of the two sets of experiments. The calculational analysis of the 55-deg results from ORNL show fairly good agreement at all energies except those near $5 \mathrm{MeV}$ where the calculations are high (see Fig. 11). The same comparison for the IRT 55-deg detector results indicate the calculations are consistently low over the whole energy range with the best agreement occurring near $5 \mathrm{MeV}$ (see Fig. 7). A similar pattern is observed in the comparisons for the 30 -deg results of both experiments. It is interesting to note that if the calculated results 
for the IRT 30- and 55-deg detectors were adjusted upward so that they were normalized to agree below $4 \mathrm{MeV}$, the comparison would be consistent with the ORNL comparisons at these angles.

In light of the above comment and the fact that it is highly unlikely that nitrogen neutron scattering data below $3 \mathrm{MeV}$ would contain errors as large as indicated by the IRT results, a series of tests were made on the modelling of the IRT experiment. An initial series of test runs indicated that the 30- and 55-deg IRT integral neutron count results are highly sensitive to the composition of the styrofoam dewar and its interception of the incident neutron beam. A calculation with the incident beam diameter equal to that of the nitrogen sphere only (i.e., $15.25 \mathrm{~cm}$ instead of the $20.82 \mathrm{~cm}$ quoted in the experiment) produced results at the $30-$ and $55-\mathrm{deg}$ detector positions which doubled the size of the original discrepencies shown in Figs. 6 and 7. The calculations at the 90- and 125-deg positions were almost completely unaffected by this change in beam diameter. Calculations were also made with the styrofoam density doubled and this smaller beam diameter, producing results substantially unchanged from those $j u s t$ described (correct styrofoam density and $15.24-\mathrm{cm}$ diameter incident neutron beam). These results indicate that the effect of the styrofoam in front of or behind the nitrogen sample relative to the incident beam direction is negligible but the effect of the outermost she1l nearest the detector position is very important for forward scattering directions. Neutrons scattering in this outer ring have few, if any, collisions with the nitrogen in the dewar before being detected. It is the forward peak scattering collisions with hydrogen in the styrofoam which causes this effect, and small discrepancies in the amount of hydrogen surrounding the nitrogen sample could cause the disagreement in the neutron count rates shown in Figs. 6 and 7 .

As a result of conclusions drawn from the model testing runs, a final calculation was performed with a $0.04-\mathrm{cm}$-thick layer of $\mathrm{H}_{2} \mathrm{O}$ surrounding the IRT dewar. The results of this calculation are shown in Figs. 14 through 17. It is clear that comparison of the calculated and measured 30- and 55-deg detector count rates now agree remarkably we11, even better 
than those for the ORNL experiment, and as expected from the other tests described, the 90- and 125-deg calculated results were relatively unaffected. This thin (16 mils) $: \mathrm{H}_{2} \mathrm{O}$ shell actually has about two-thirds the hydrogen content of the 1-in.-thick styrofoam dewar, and it is the forward scattering from the hydrogen in the $\mathrm{H}_{2} \mathrm{O}$ in the outermost shel1, where the neutron beam encounters no. nitrogen, that causes the increase in the calculated count rate at the forward detectors. It is believed that this $\mathrm{H}_{2} \mathrm{O}$ shell could exit in the IRT experiment as a result of ice formation or condensation on the cold dewar. The narrow beam used in the ORNL experiment would preclude this effect from perturbing the ORNL results and thus could explain the inconsistency between the two experiments.

\section{B. Integral Gamma-Ray Results}

Examination of the gamma-ray count results shown in Figs. 6 through 13 indicates excellent agreement between calculation and experiment at all angles and energies in both experimental setups. Only at energies below the inelastic threshold, where only the counts resulting from neutroninduced gamma rays in the $\mathrm{NE}-213$ detector appear, is there any disagreement. In the ORNL experiment the neutron-induced gamma rays have been. removed from the results by the experimentalist. In the IRT experimental results, the induced gamma rays were not removed and an empirical relationship was included in the calculation to account for this gamma-ray production mechanism. As is evident, however, there is an unexplained low-energy discrepancy in the IRT gamma-ray count rate comparisons due to the neutroninduced gamma rays. This discrepancy is lowest at the backward angle and increases as the angle becomes more forward. This variation is in large measure a result of the disagreement in the neutron count-rate curves at the forward angles since the gamma-ray disagreement is neutron induced. In any event, the gamma-ray results should dispell any further controversy about the adequacy of the ENDF/B-IV nitrogen gamma-ray production files. 8 


\section{Secondary Neutron Energy Spectra Results}

In an effort to more thoroughly examine the nitrogen cross-section data and explain the disagreements in the integral neutron count rate comparisons, secondary neutron energy spectra were calculated for all detector angles as a function of incident neutron energy. Figures 18, 19, and 20 give the neutron flux spectrum comparisons for the IRT 125-deg detector position. The spectra units are flux per incident neutron per $\mathrm{cm}^{2}$ of sample area as a function of the mid-point energy of broad incident neutron energy bins. These curves reflect the generally good agreement seen in the 125-deg integral neutron results (Fig. 9). The calculational results in the valley between the elastic and inelastic peaks, at the highest and next highest energies respectively, in Figs. 19 and 20, are due entirely to an empirical detector energy resolution function. In Fig. 20 the calculated results for incident energies of between 10 and 15 $\mathrm{MeV}$ are low in the elastic peaks and high in the inelastic tails of the spectra. These two discrepancies, when translated into integral count rates by multiplying the detector efficiency ( $T a b l e ~ I$ ), result in the overprediction of the integral count rate at high energies as shown in Fig. 9 due to the larger efficiencies for counting the low energy inelastically scattered neutrons. The integral count discrepancies thus appear to be the result of two regions of discrepancy in the cross-section data.

The ORNL neutron flux spectra comparisons are shown in Figs. 21 through 32 in units of flux per incident neutron versus incident neutron energy. The 125-deg curves shown in Figs. 30, 31, and 32 are in good relative agreement with the corresponding IRT results given in Figs. 18, 19 , and 20 as expected from the comparisons of the integral neutron results. The 55-deg ORNL flux curves (Figs. 24, 23, and 26) exhibit the same characteristics discussed above for the high-energy results in the IRT 125-deg spectra comparisons. Examination of the flux comparison for the 4 to 5 $\mathrm{MeV}$ incident neutron energy range in Fig. 24 indicates that the only substantial disagreement is on the high-energy side of the elastic peak. This disagreement must in large measure be the cause of the lack of agreement between the calculated and experimental integral results in the 
dip near $5 \mathrm{MeV}$ in Fig. 11. However, there may be some lower-energy contribution to this disagreement due to the discrepancies in the spectra comparison below $4 \mathrm{MeV}$ (see Fig. 24) since the detector efficiencies increase substantially at lower energies.

In the 30-deg ORNL neutron spectra results shown in Figs. 21, 22, and 23, the 4 to $15 \mathrm{MeV}$ incident energy range all exhibit overpredictions for the calculations of the high-energy side of the elastic scattering peak. It would seem that these disagreements give rise in large measure to the disagreements observed in the integral results above $4 \mathrm{Mev}$ in Fig. 10 .

The ORNL 90-deg neutron spectra comparisons shown in Figs. 27, 28, and 29 are in generally good agreement and the comments concerning the 125-deg ORNL spectra results also apply to the 90-deg results.

\section{Gamma-Ray Secondary Spectra Results}

The ORNL gamma-ray flux spectra comparisons shown in Figs. 33 through 44 are in generally good agreement. Only at the lowest energies is there a breakdown in the comparison due to the absence of any real experimentally significant data. In general, the calculations are lower near the experimental peaks and higher near the valleys, but the integral comparisons of these curves is quite good as indicated in the gamma-ray count rate curves in Figs. 10 to 13. This smoothing effect is a combination of the broad energy groups used In the calculation, the multigroup theory treatment itself, and the application of the energy resolution function given in Eq. (2). The calculated gamma-ray integral results are slightly higher than the experimental results near $15 \mathrm{MeV}$ at all angles, but it is not apparent what causes this since the $12.5-15 \mathrm{MeV}$ spectra shown in Figs. 35, 38, 41, and 44 are high for the lowest and highest secondary gamma-ray energies where the detector efficiencies (Table I) are lowest. 


\section{Conclusions}

The current ENDF/B-IV nitrogen gamma-ray production crosssection data seems to be in good order in contrast to 1ts status in the past; and it now appears that the neutron data files contain some significant discrepancies. These experiments and calculations clearly show that the neutron data file above $9 \mathrm{MeV}$ has deficiencies in both the elastic and inelastic cross sections. Discounting the IRT 30- and 55-deg integra1 neutron calculations due to the presence of some low $\mathrm{Z}$ material in the experiment (it is possible that a thin layer of frost condensed on the dewar during the IRT experiment), the nitrogen neutron cross sections below $9 \mathrm{MeV}$ seem to be adequate except for the forward angle elastic scattering data around $5 \mathrm{MeV}$. The secondary energy spectra results show that these 5-MeV forward angle discrepancies are due to the elastic scattering data. Reevaluation and/or remeasurement of the elastic and nonelastic cross sections around the $5-\mathrm{MeV}$ total cross section minimum is certainly called for due to the great importance of this energy range in air transport calculations. 9 


\section{References}

1. L. Harris, Jr., G. L. Trimble, and J. C. Young, "Integral Experiments to Test Carbon and Nitrogen Cross Sections," Intelcom Radiation Technology Report DNA-2986F (1972).

2. G. L. Morgan, "Mẹasurement of Secondary Neutrons and Gamma Rays Produced by Neutron Interactions with Nitrogen and Oxygen Over the Incident Energy Range 1 to $20 \mathrm{MeV}, "$ ORNL-TM-5023 (1975).

3. S. N. Cramer and E. M. Oblow, "Analysis of Neutron Scattering and Gamma-Ray Production Integral Experiments on Carbon for Neutron Energies from 1 to $15 \mathrm{MeV}, "$ Nucl. Sci. Eng. 58, 33 (1975).

4. E. A. Straker et al., "The MORSE Code - A Multigroup Neutron and Gamma-Ray Monte Carlo Transport Code," ORNL-4585 (1970).

5. N. M. Greene et al., "AMPX: A Modular Code System for Generating Coupled Neutron - Gamma Libraries from ENDF/B," ORNL-TM-3706 (1974).

6. L. Harris, Jr., and J. C. Young, "Energy Spectrum Measurements of Scattered Neutrons from Nitrogen," Trans. Am. Nucl. Soc., 17, 550 (1973).

7. C. L. Thompson and E. A. Straker, "OGR-ACTIFK, Monte Carlo Neutron Transport Code," private communications (1969).

8. F. G. Perey and J. K. Dickens, "Is There Still a Nitrogen CrossSection Discrepancy," ORNL-TM-4216 (1973).

9. D. E. Bartine, E. M. Oblow, and F. R. Mynatt, "Radiation Transport Cross-Section Sensitivity Analysis - A General Approach I1lustrated for a Thermonuclear Source in Air," Nuc1. Sci. Eng. 55, 147 (1974). 


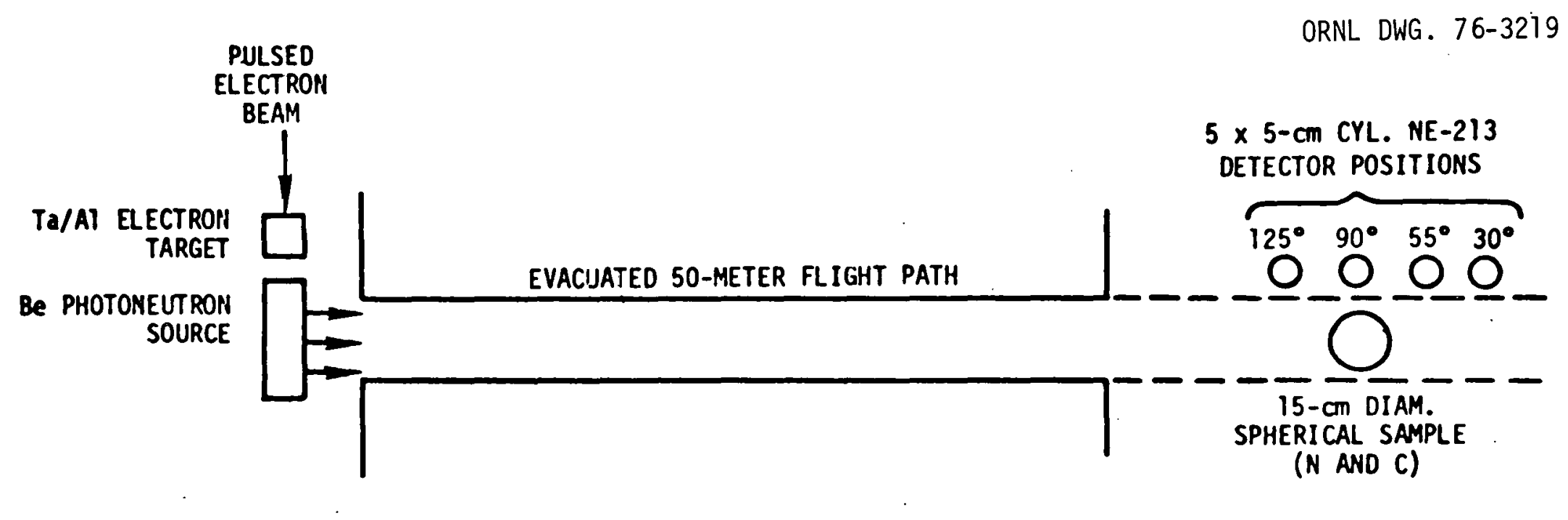

RT-01353

Fig. 1. Neutron Flight Path and Source Geometry for IRT Integral Experiments. 
STYROFOAM LIQUID NITROGEN RESERVOIR

ORNL DWG. $76-3220$

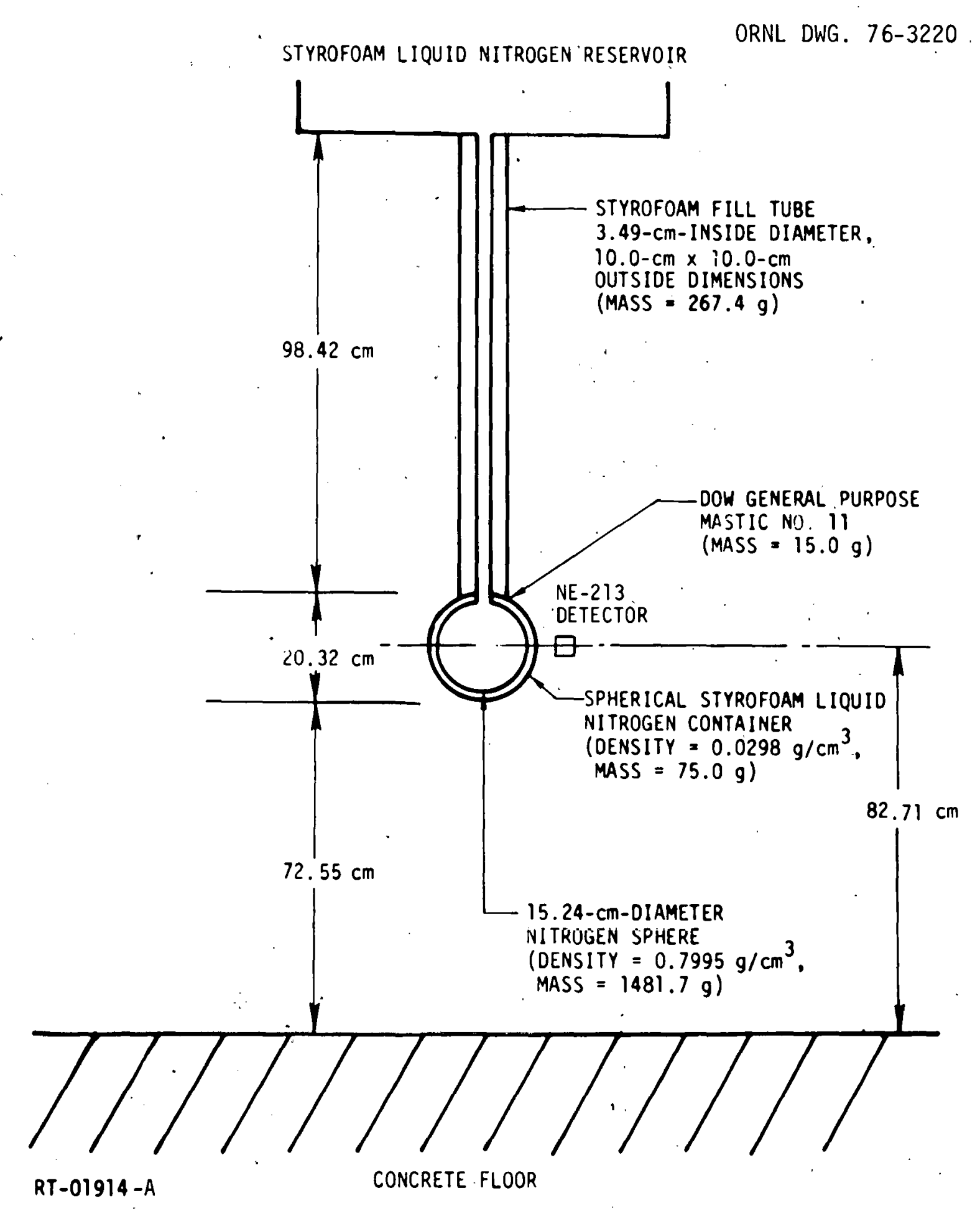

Fig. 2. End View of Nitrogen Dewar and Detector Geometry in the IRT Experiment. 
4.60-cm-HIGH $\times$ 4.65-cm-DIAMETER NE-213 DETECTOR POSITIONS

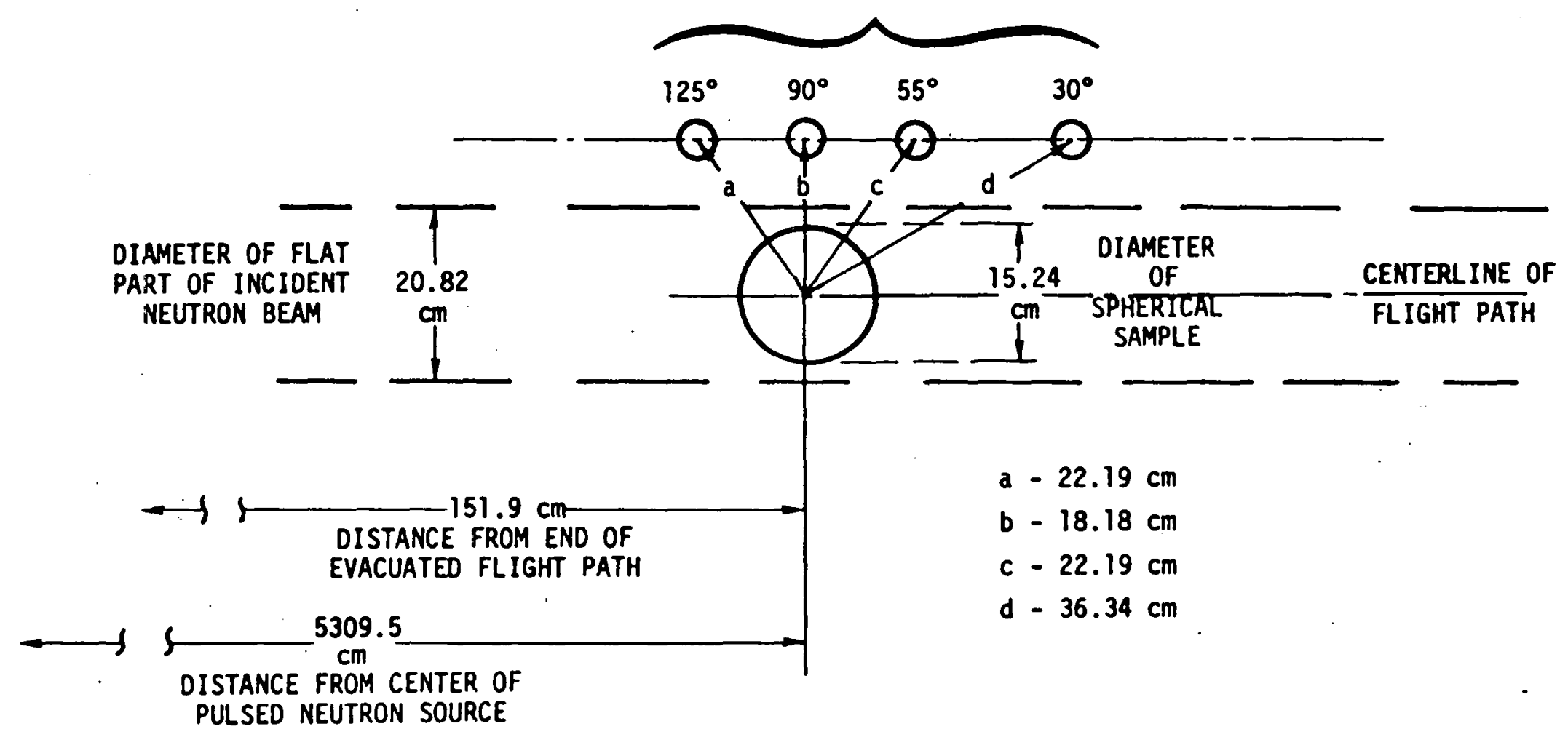

RT-01913

Fig. 3. Top View of Sample-Detector Geometry at End of 50-Meter Flight Path in IRT Experiment. 


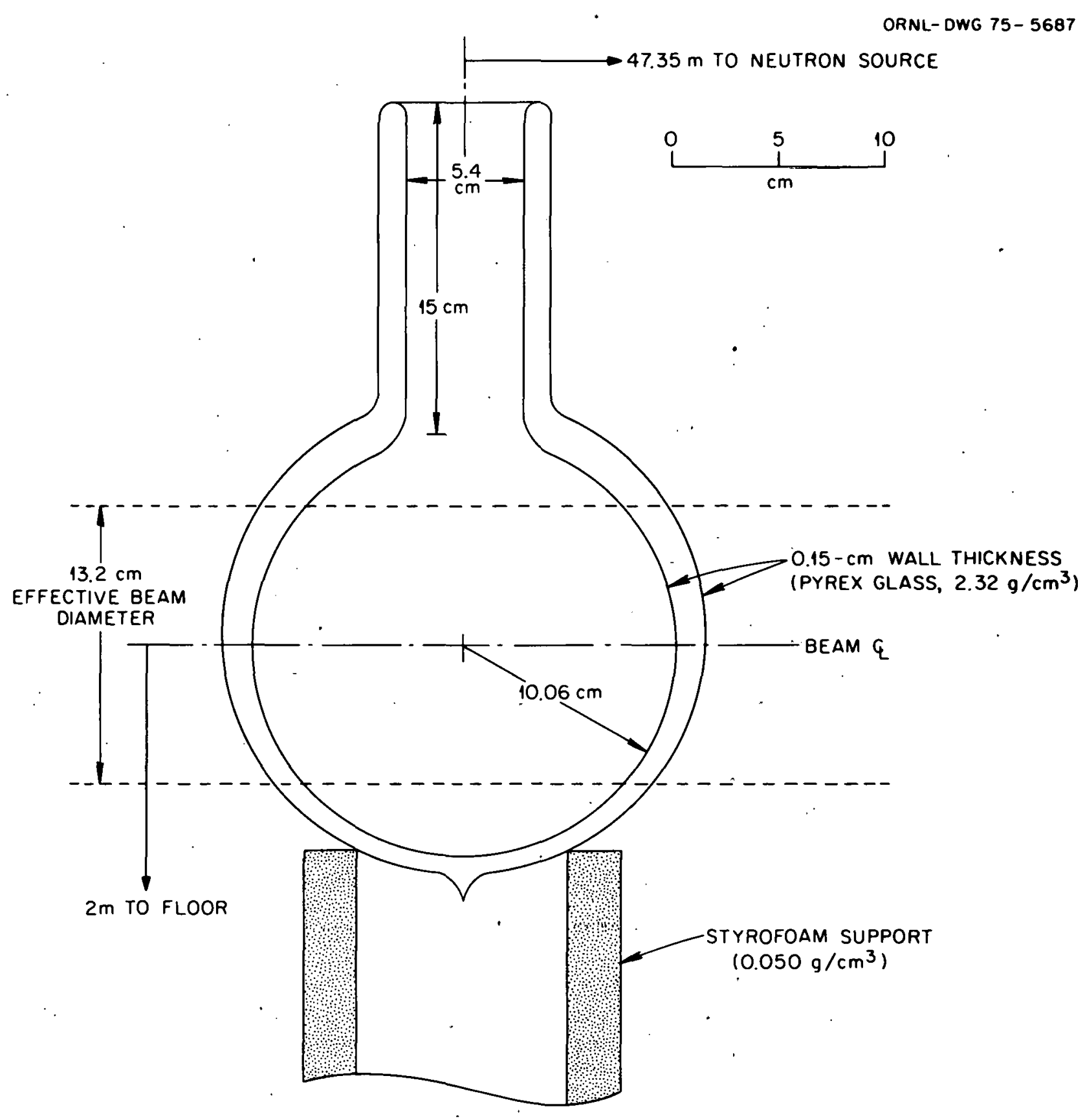

Fig. 4. Geometry of Nitrogen Dewar Used in the ORNL Experiment. 


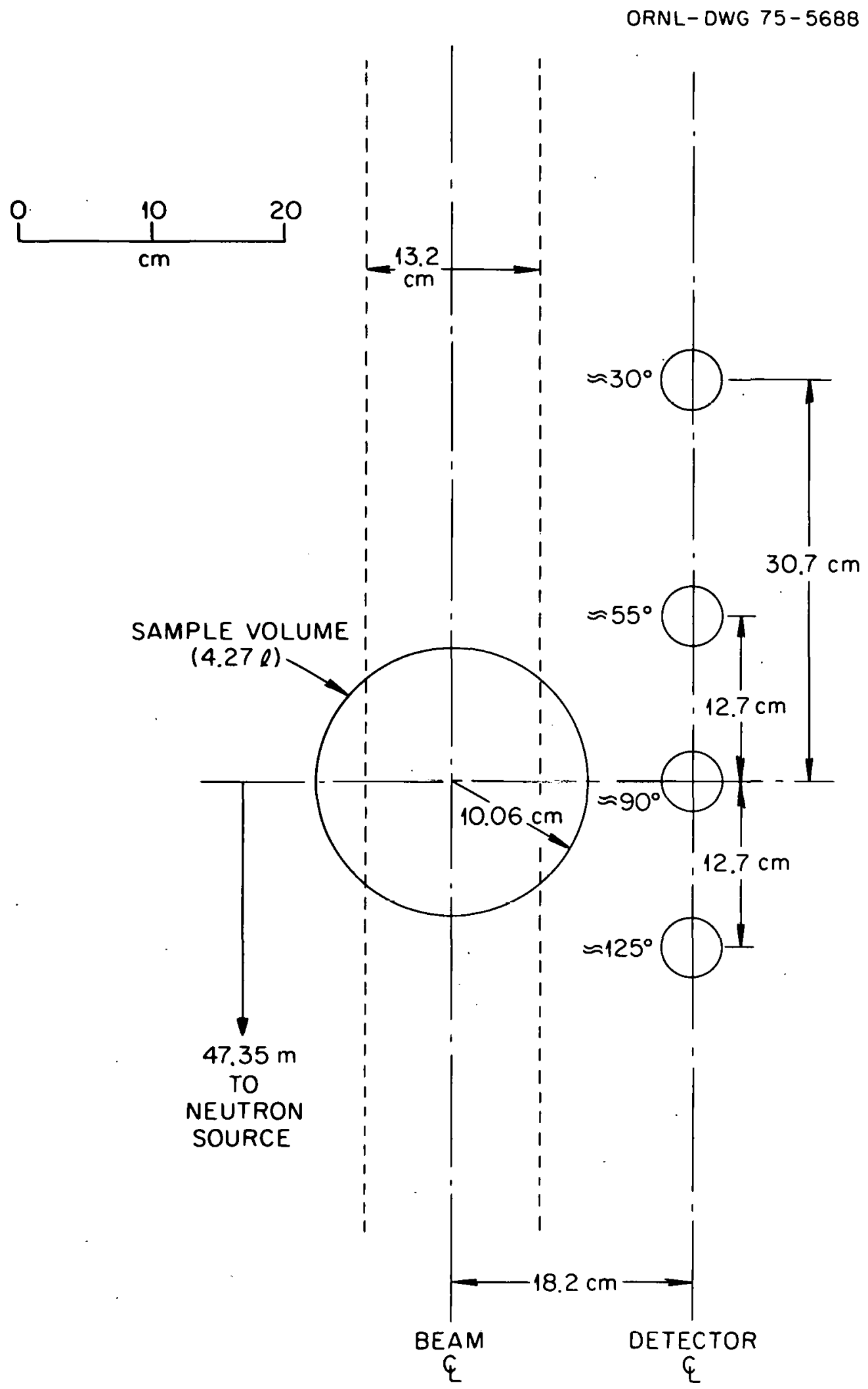

Fig. 5. Top View of Nitrogen Dewar and Detectors in ORNL Experiments. 


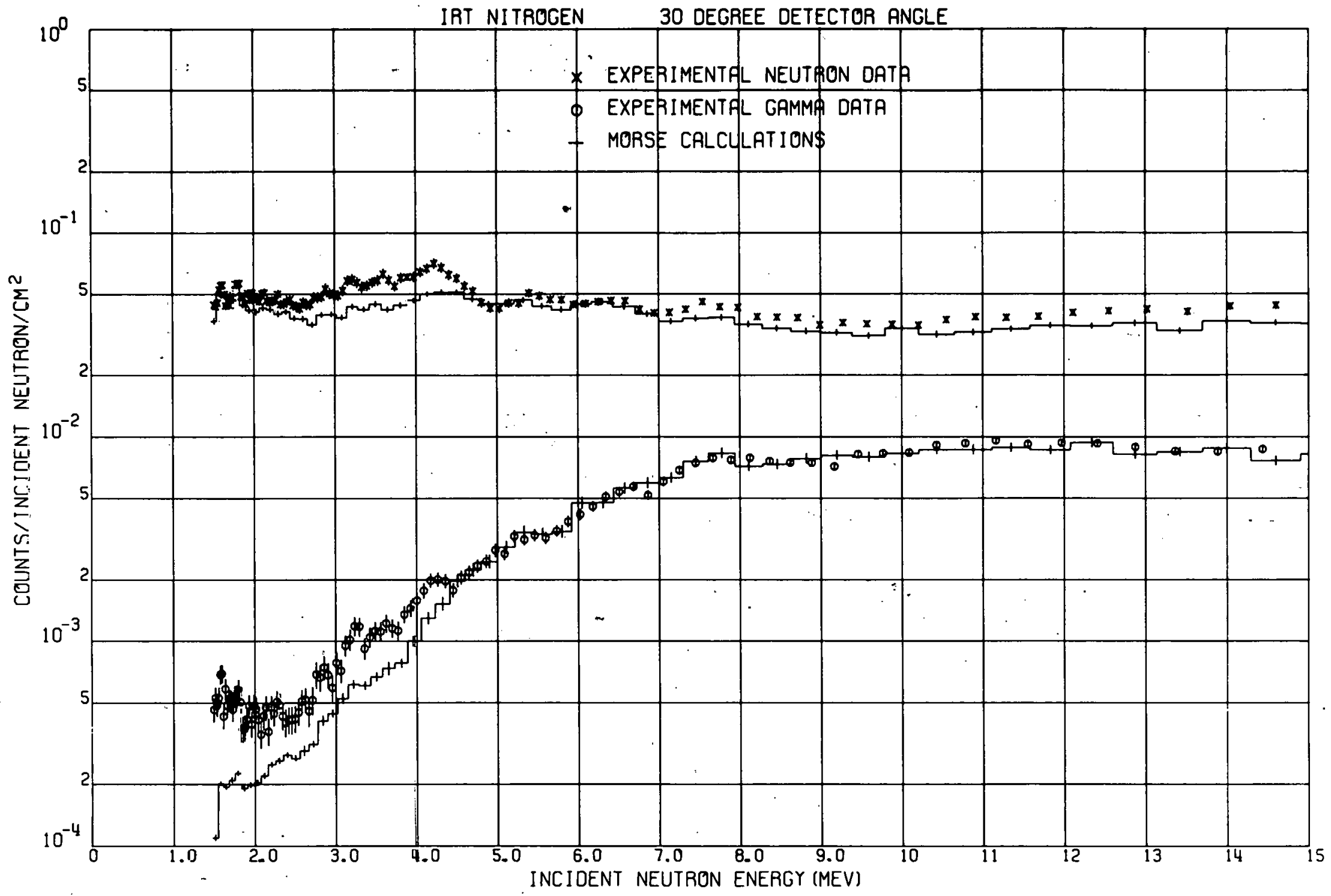

Fig. 6. Comparison of IRT Sphere Integral Results at $30 \mathrm{deg}$ with Calculations Using ENDF/B-IV Nitrogen Data. 


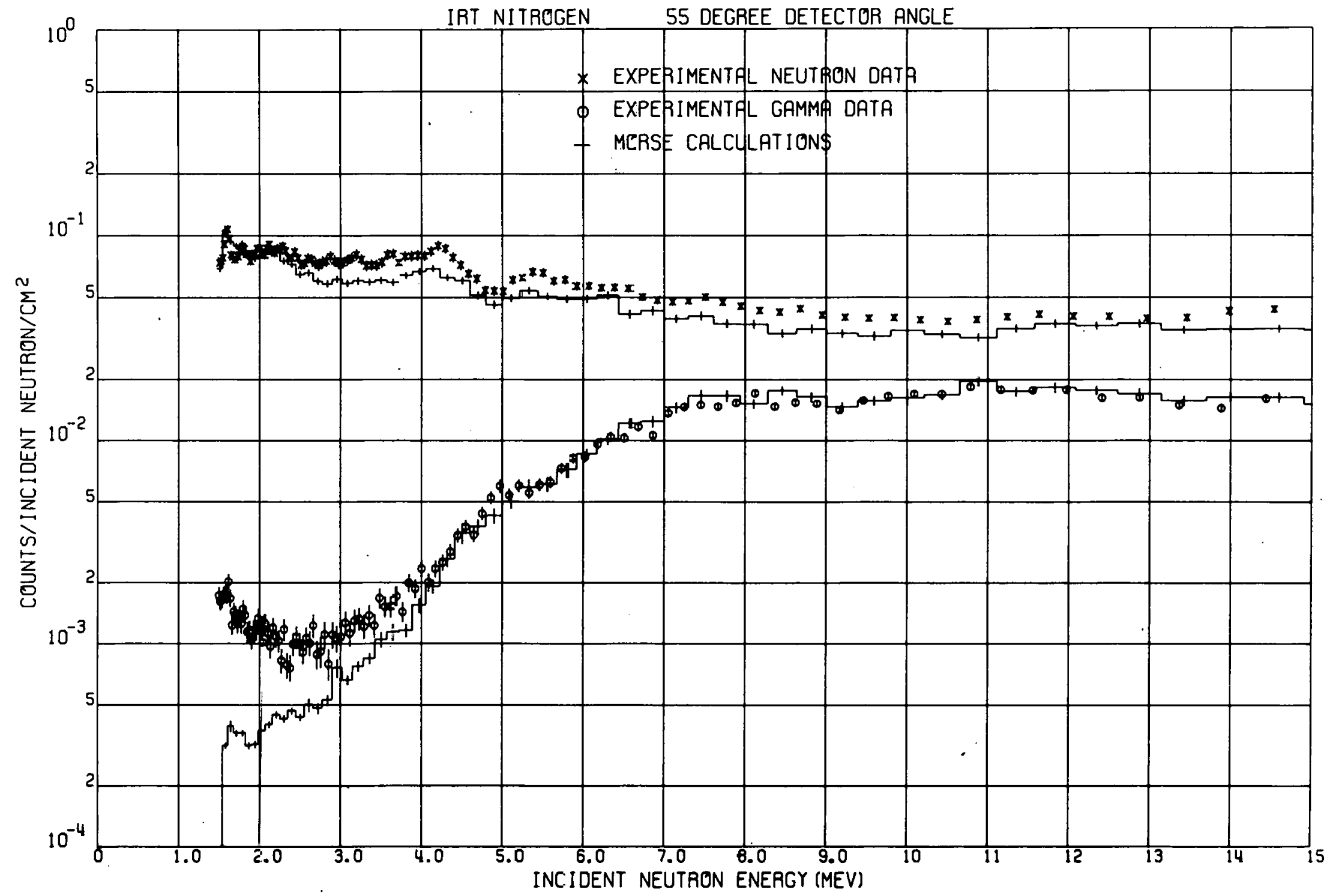

Fig. 7. Comparison o乏 IRT Sphere Integral Results at $55 \mathrm{deg}$ with Calculations Using ENDF/B-IV Nitrogen Data. 


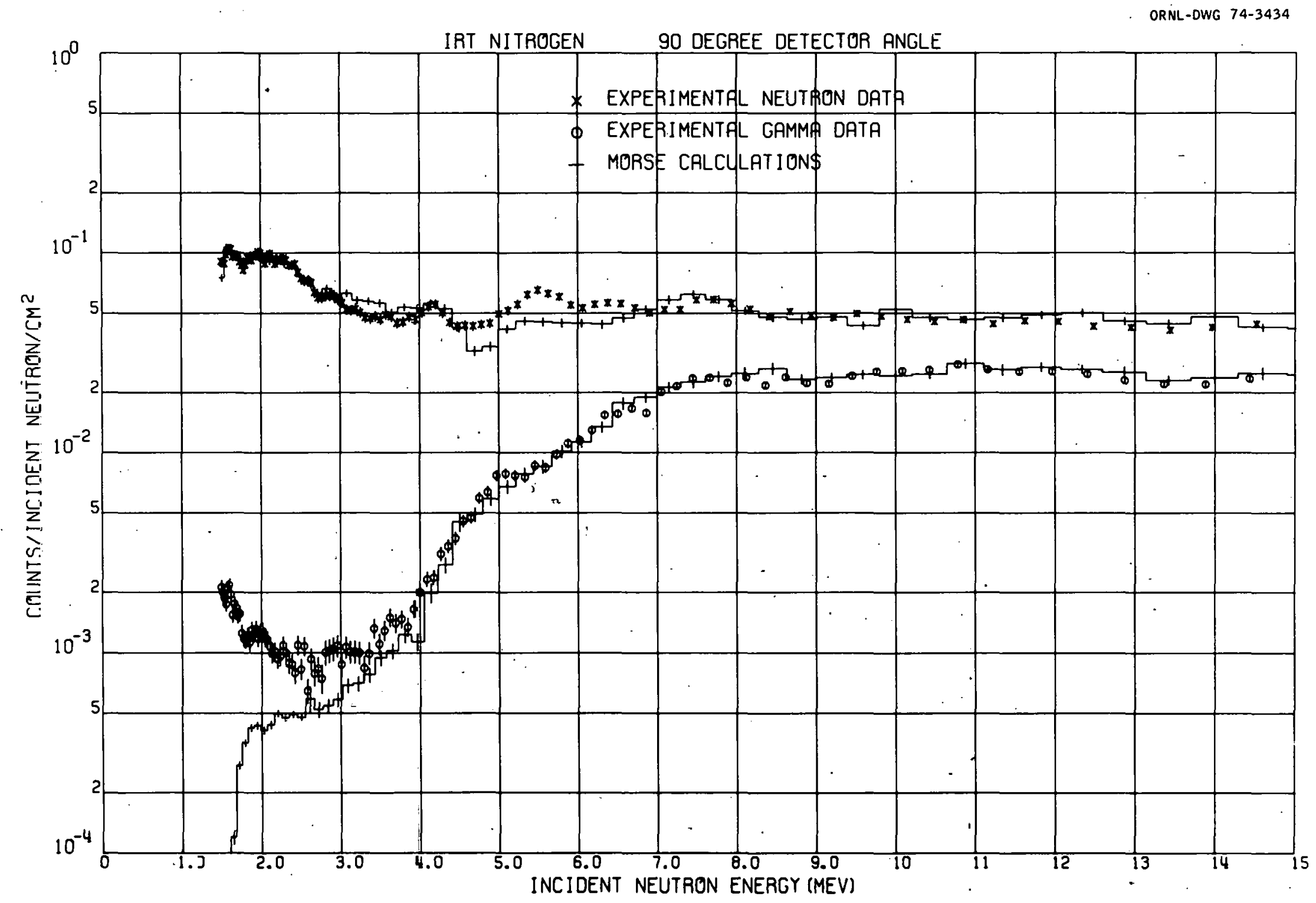

Fig. 8. Comparison of IET Sphere Integral Results at 90 deg with Calculations Using ENDF/B-IV Nitrogen Data. 


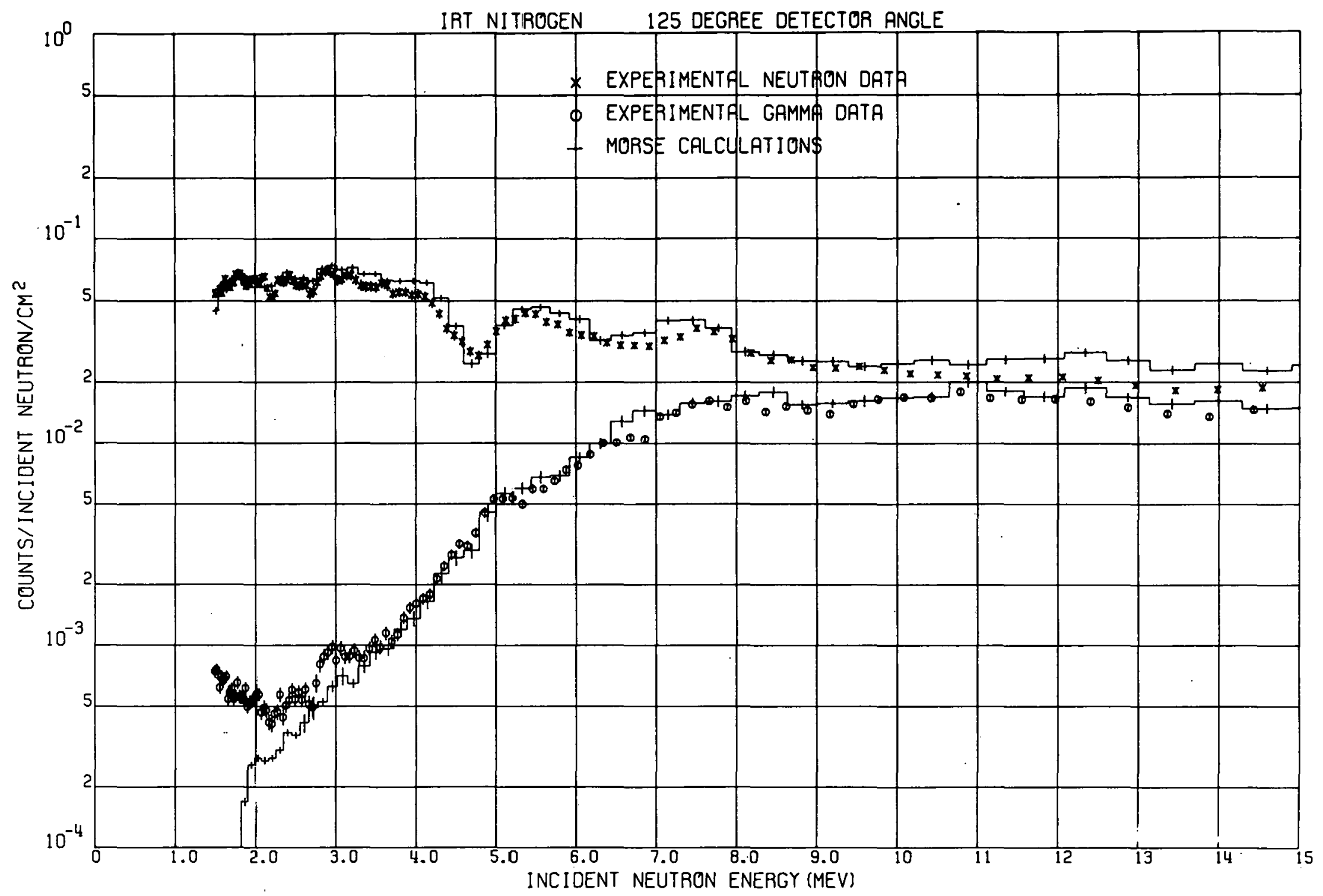

Fig. 9. Comparison of IRT Sphere Integral Results at $125 \mathrm{deg}$ with Calculations Using ENDF/B-IV Nitrogen Data. 


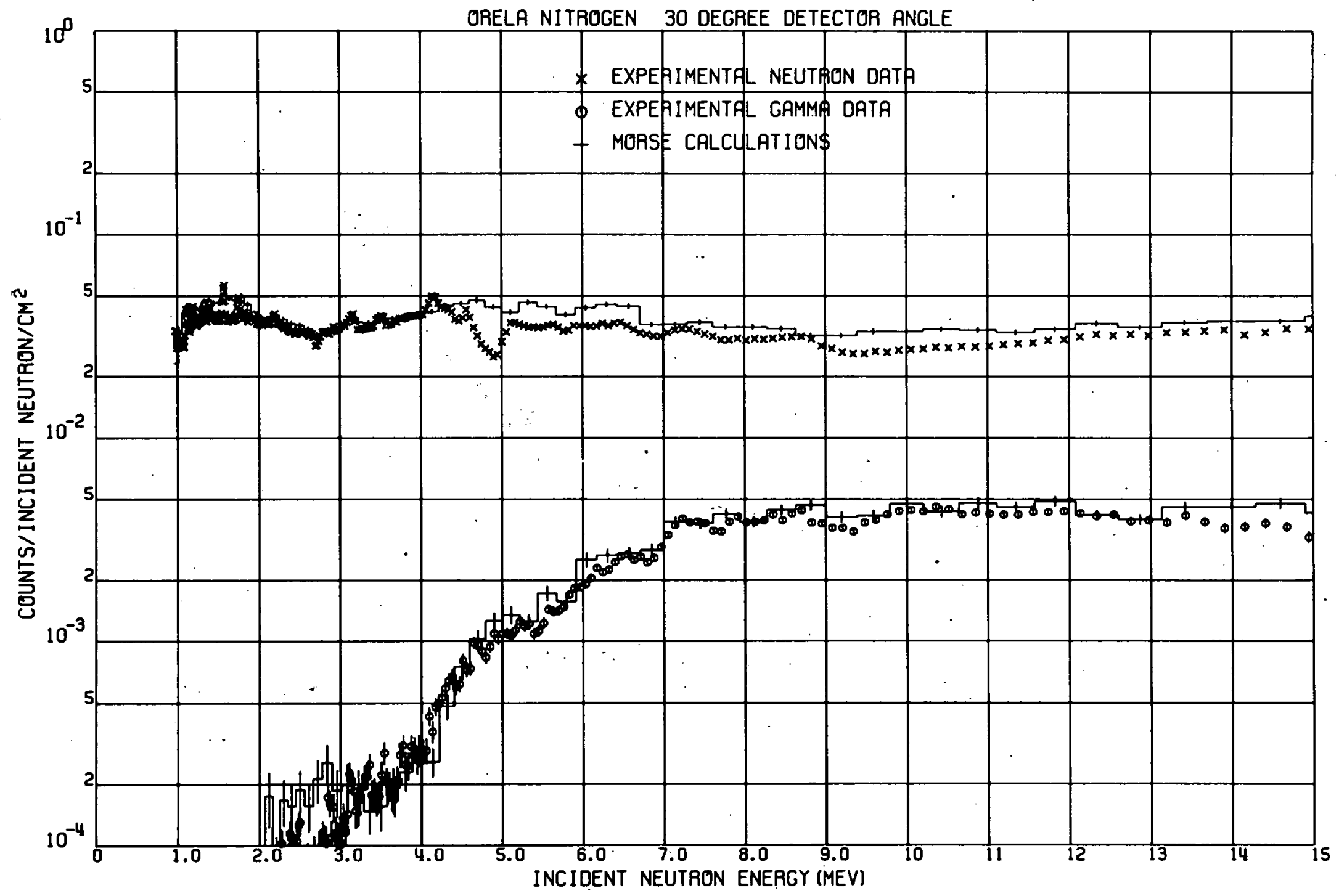

Fig. 10. Comparison of ORNL Sphere Integral Results at 30 deg with Calculations Using ENDF/B-IV Nitrogen Data. 


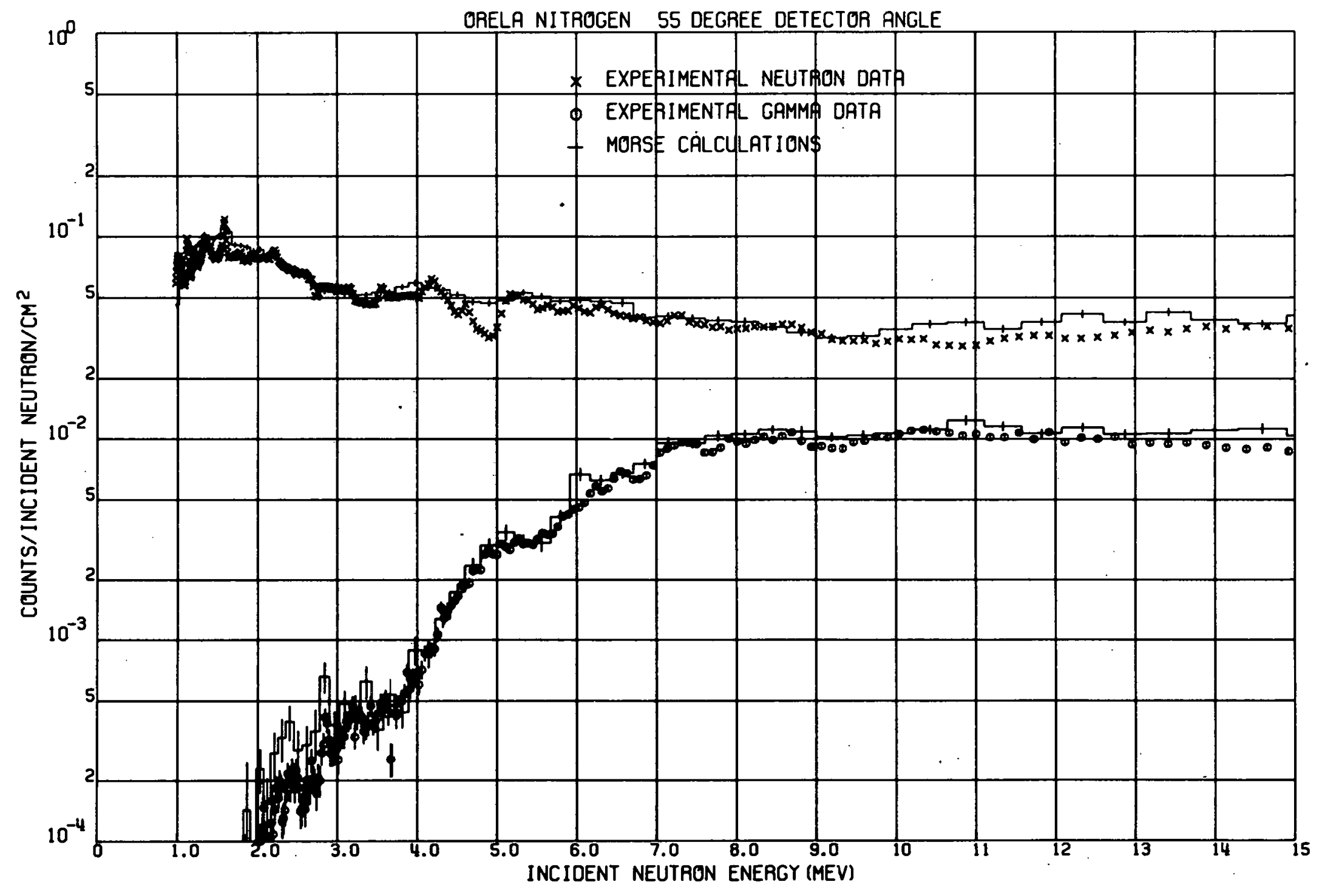

Fig. 11. Comparison of CRNL Sphere Integral Results at 55 deg with Calculations Using ENDF/B-IV Nitrogen Data. 


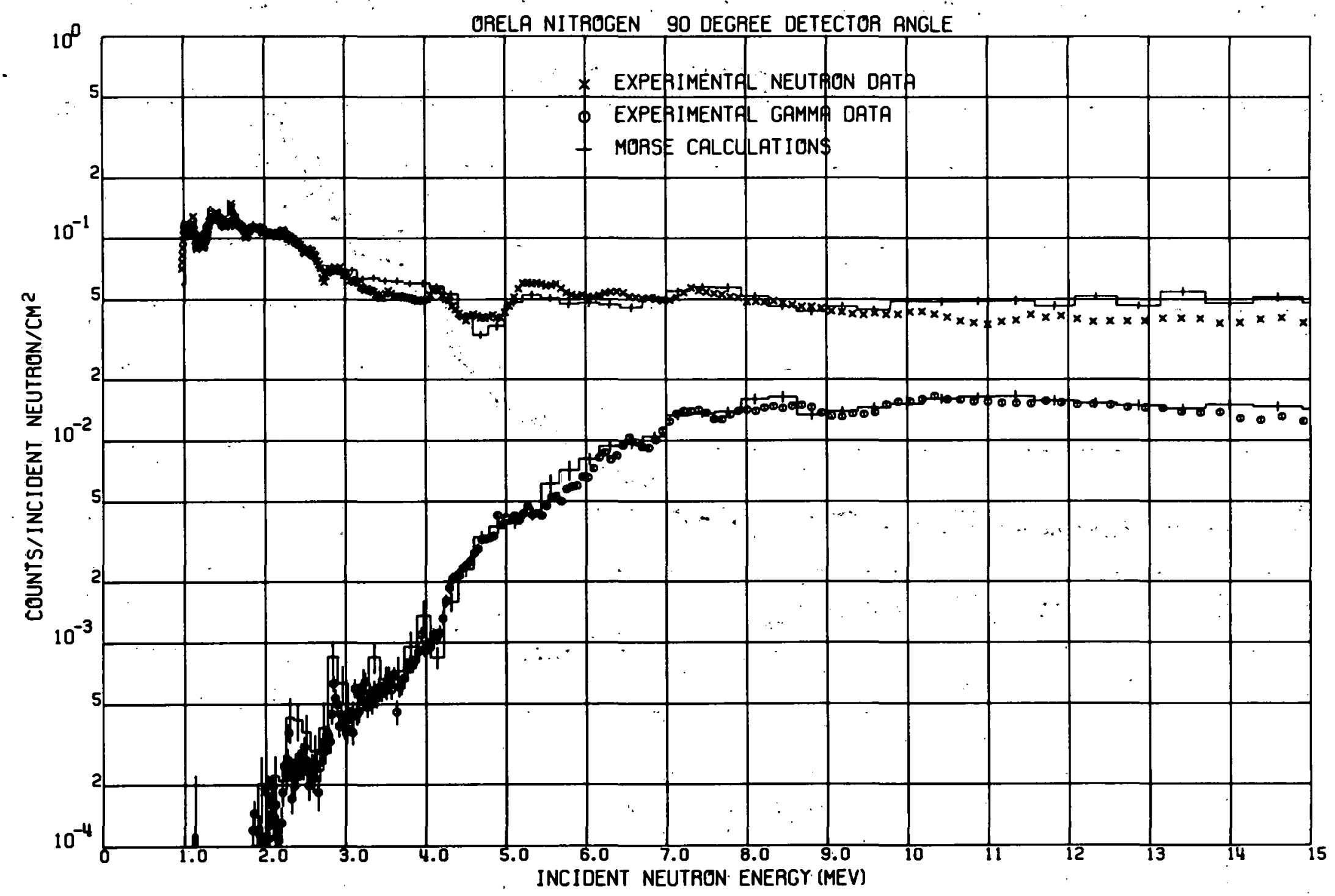

Fig. 12. Comparison of ORNL Sphere Integral Results at 90 deg with Calculations Using ENDF/B-IV Nitrogen Daca. 


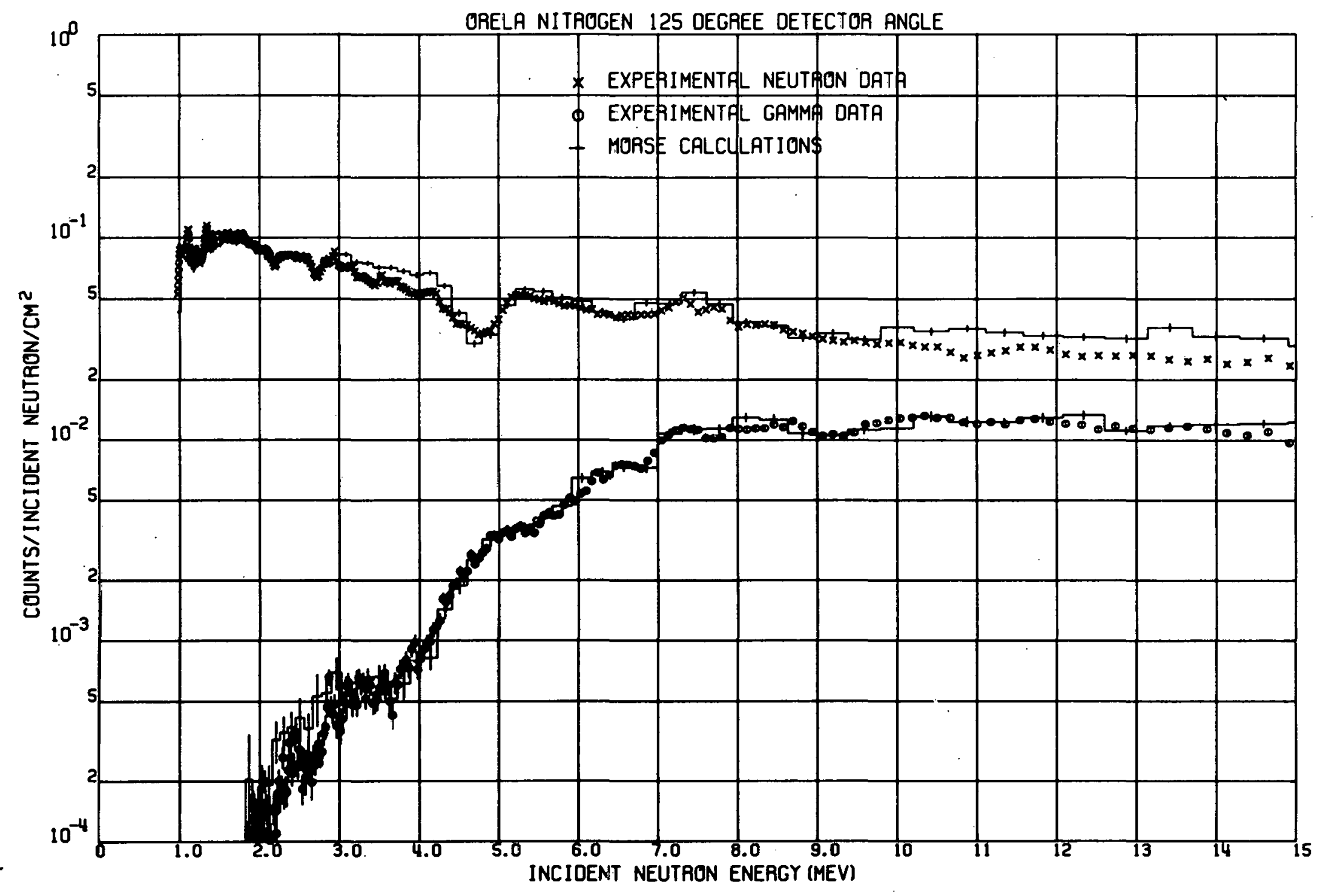

Fig. 13. Comparison of ORNL Sphere Integral Results at 125 deg with Calculations Using ENDF/B-IV Nitrogen Data. 


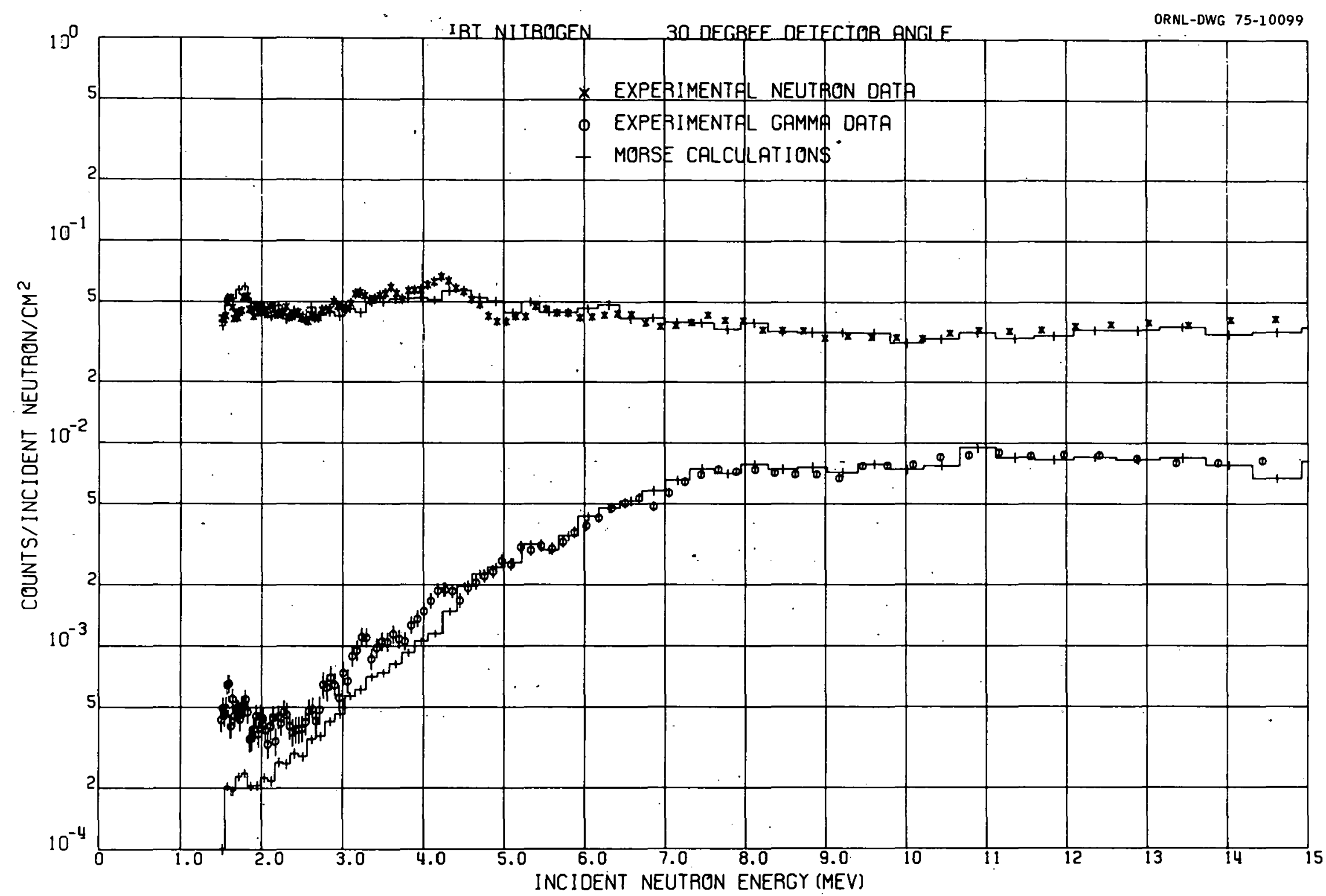

Fig. 14. Comparison of IRT Sphere Integral Results at $30 \mathrm{deg}$ with Calculations Using ENDF/B-IV Nitrogen Data and a Dewar with $\mathrm{H}_{2} \mathrm{O}$ on the Outer Surface. 


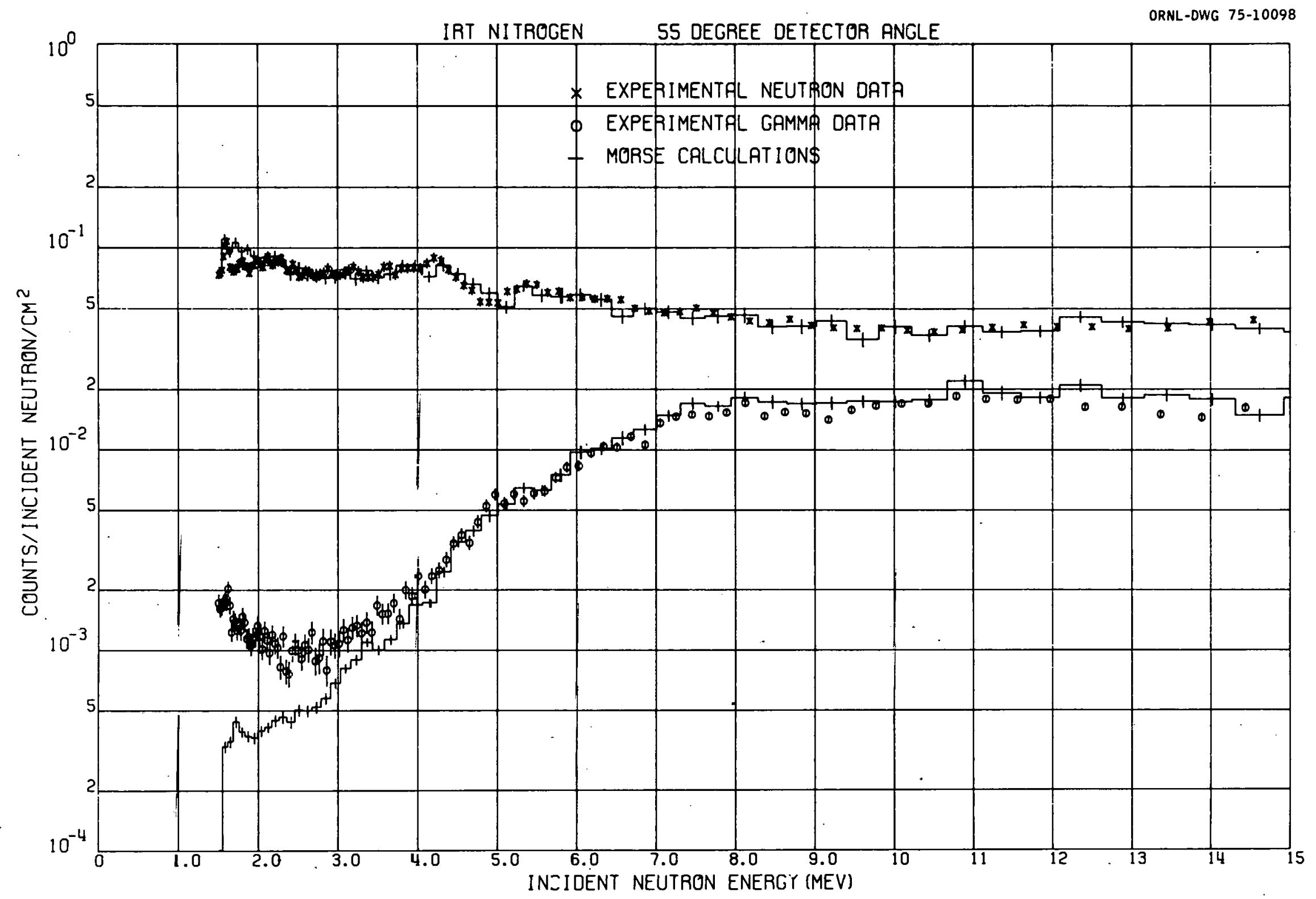

Fig. 15. Comparison of IRT Sphere Integral Results at $55 \mathrm{deg}$ with Calculations Using ENDF/B-IV Nitrogen Data and a Dewar with $\mathrm{H}_{2} \mathrm{O}$ on the Outer Surface. 


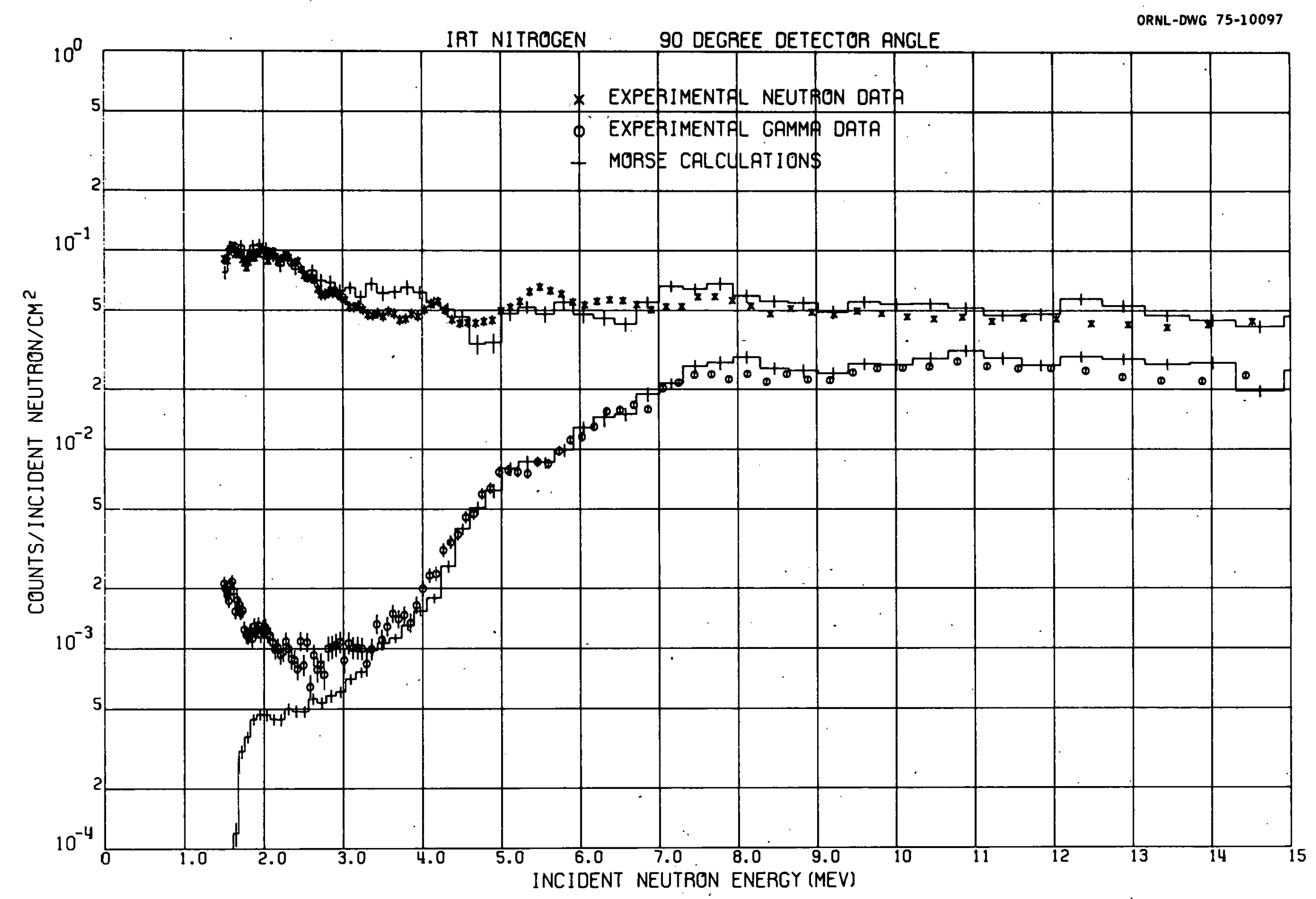

Fig. 16. Comparison of IRT Sphere Integral Results at 90 deg with Calculations Using ENDF/B-IV Nitrogen Data and a Dewar with $\mathrm{H}_{2} \mathrm{O}$ on the Outer Surface. 


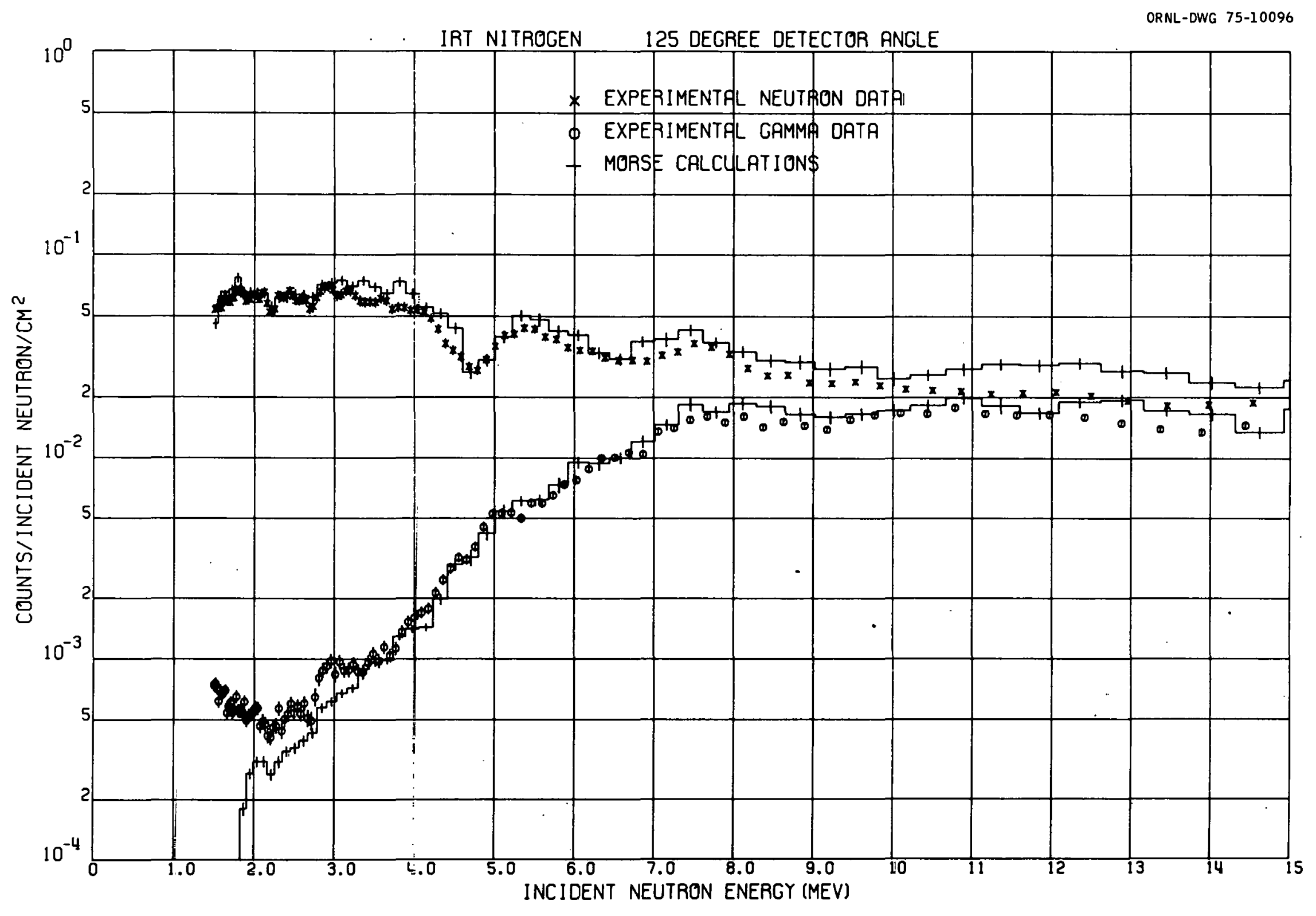

Fig. 17. Comparison of IRT Sphere Integral Results at 125 deg with Calculations Using ENDF/B-IV Nitrogen Data and a Dewar wi $=h \mathrm{H}_{2} \mathrm{O}$ on the Outer Surface. 
ORNL-DWG 74-1614R

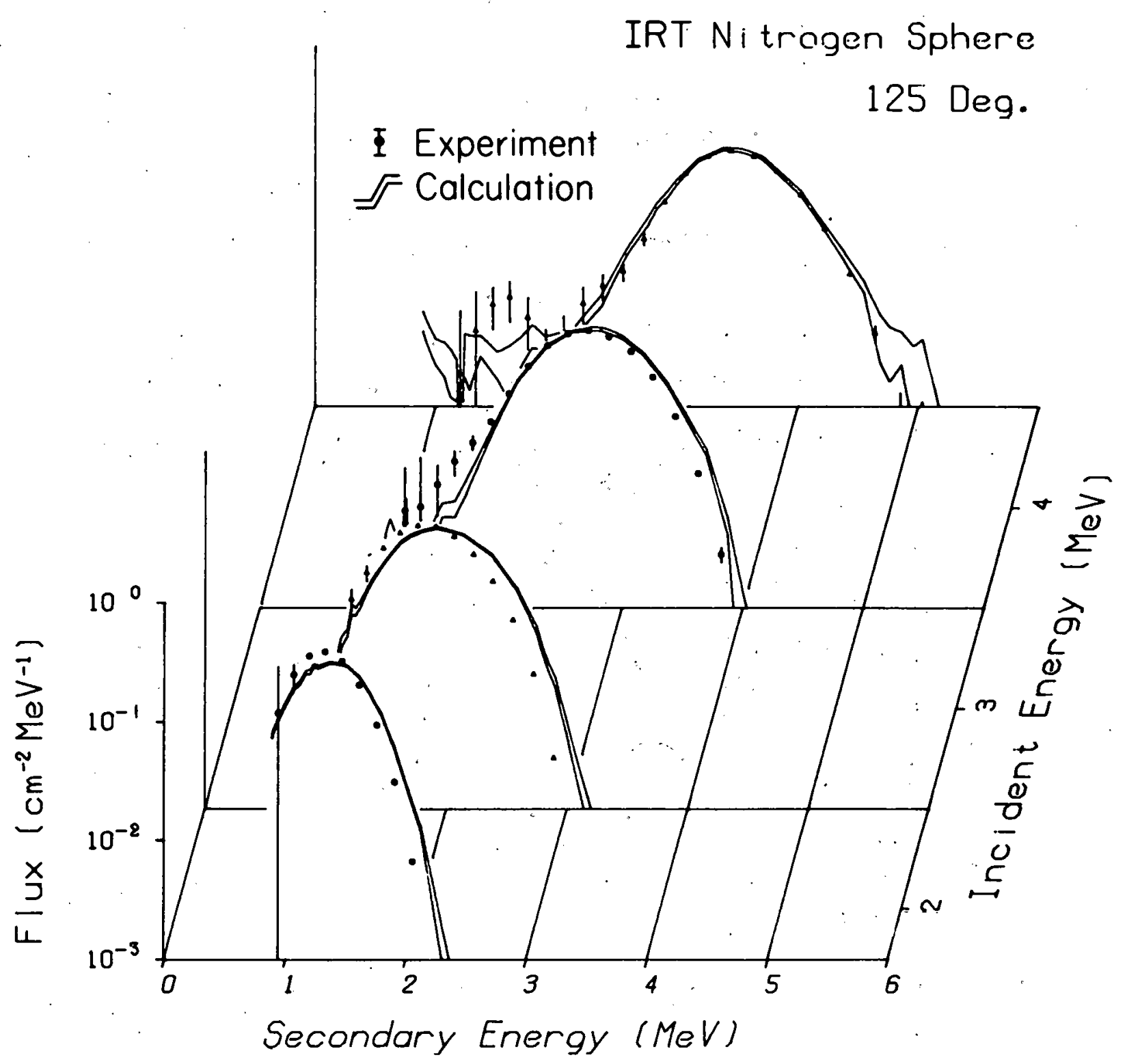

Fig. 18. IRT Sphere Secondary Neutron Spectra at 125 deg Compared with Calculations Using ENDF/B-IV Nitrogen Data. 
ORNL-DWG 74-1615R

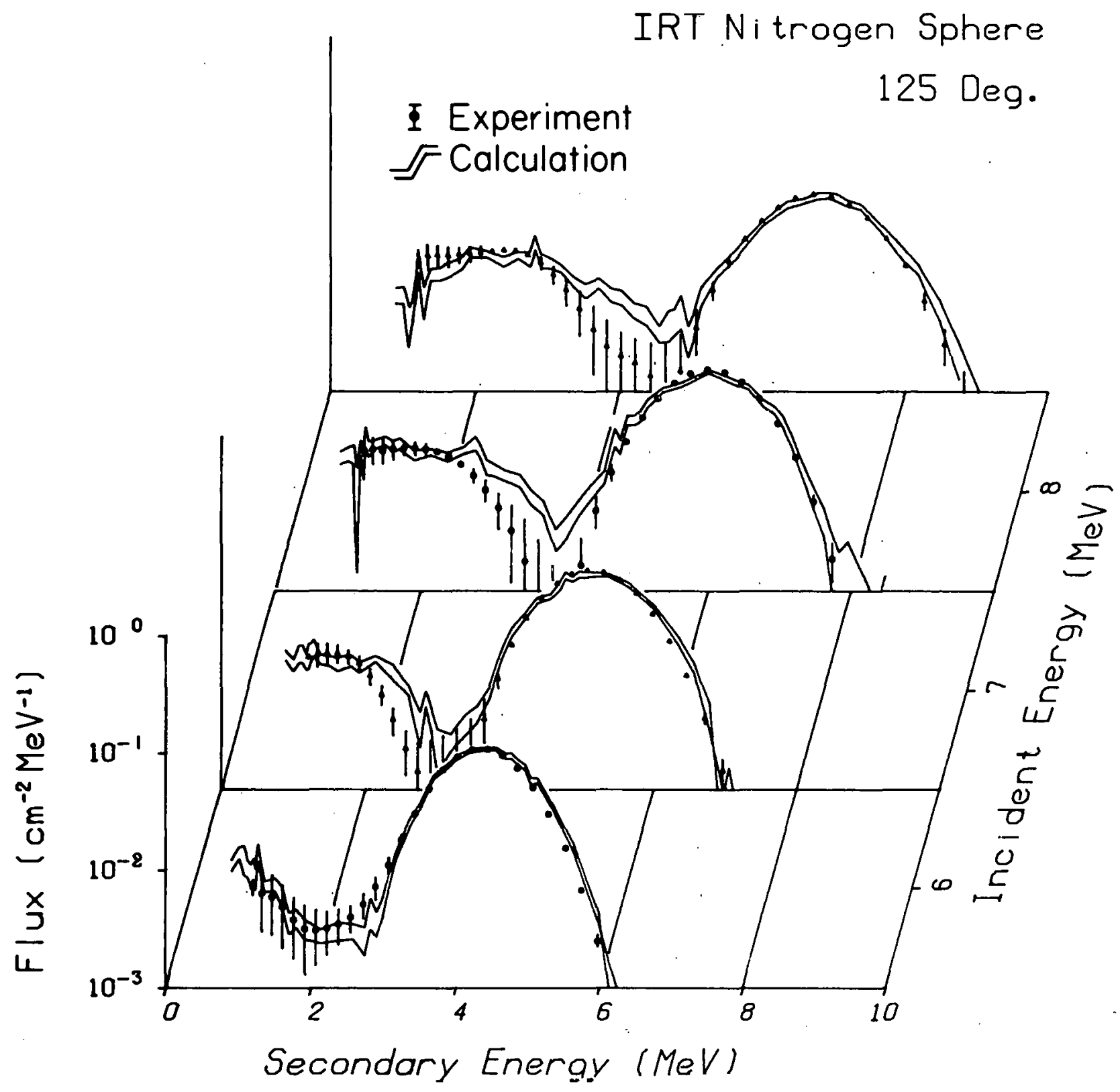

Fig. 19. IRT Sphere Secondary Neutron Spectra at 125 deg Compared with Calculations Using ENDF/B-IV Nitrogen Data. 


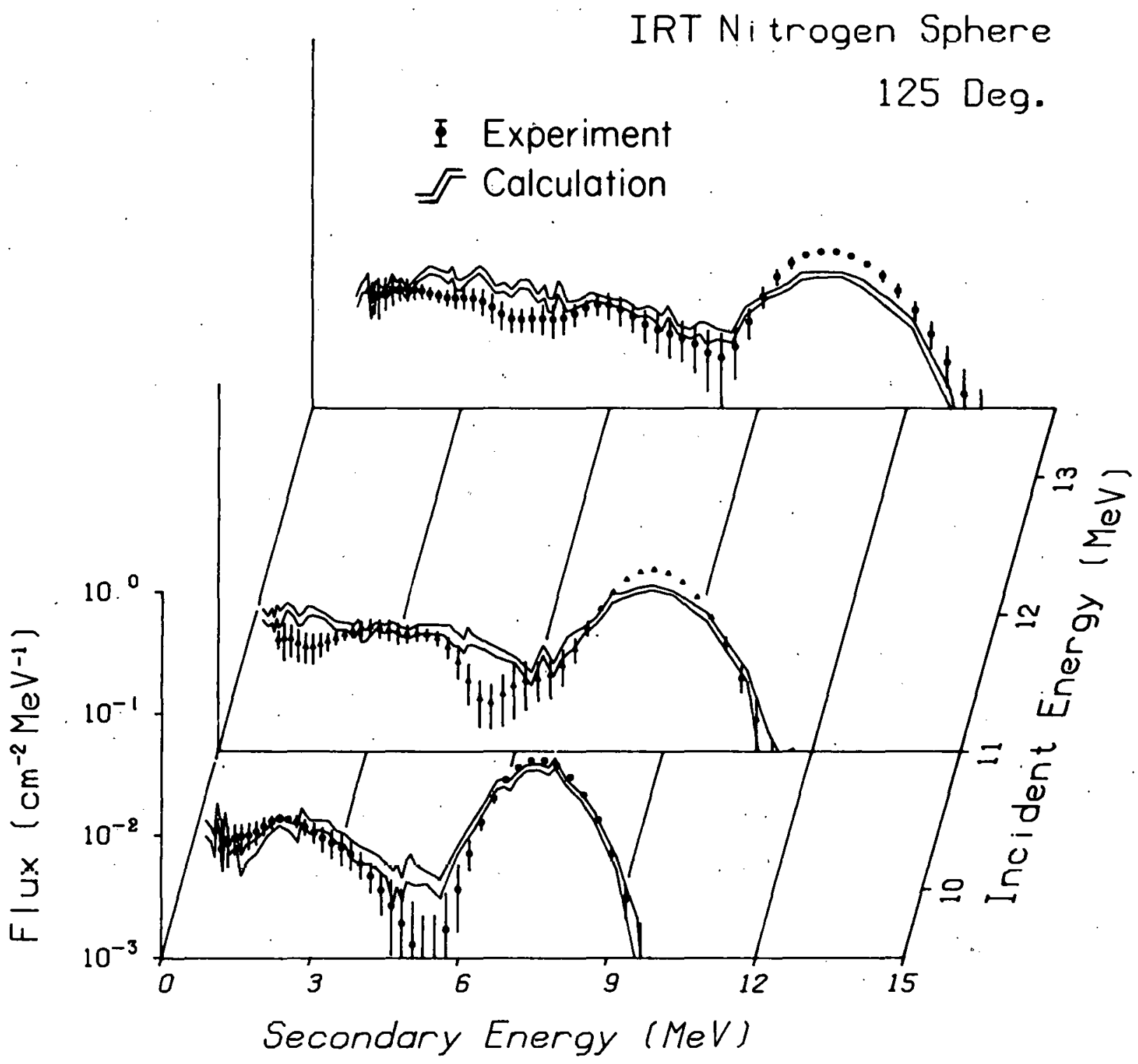

Fig. 20. IRT Sphere Secondary Neutron Spectra at 125 deg Compared w1th Calculations Using ENDF/B-IV Nitrogen Data. 
ORNL DWG 11247

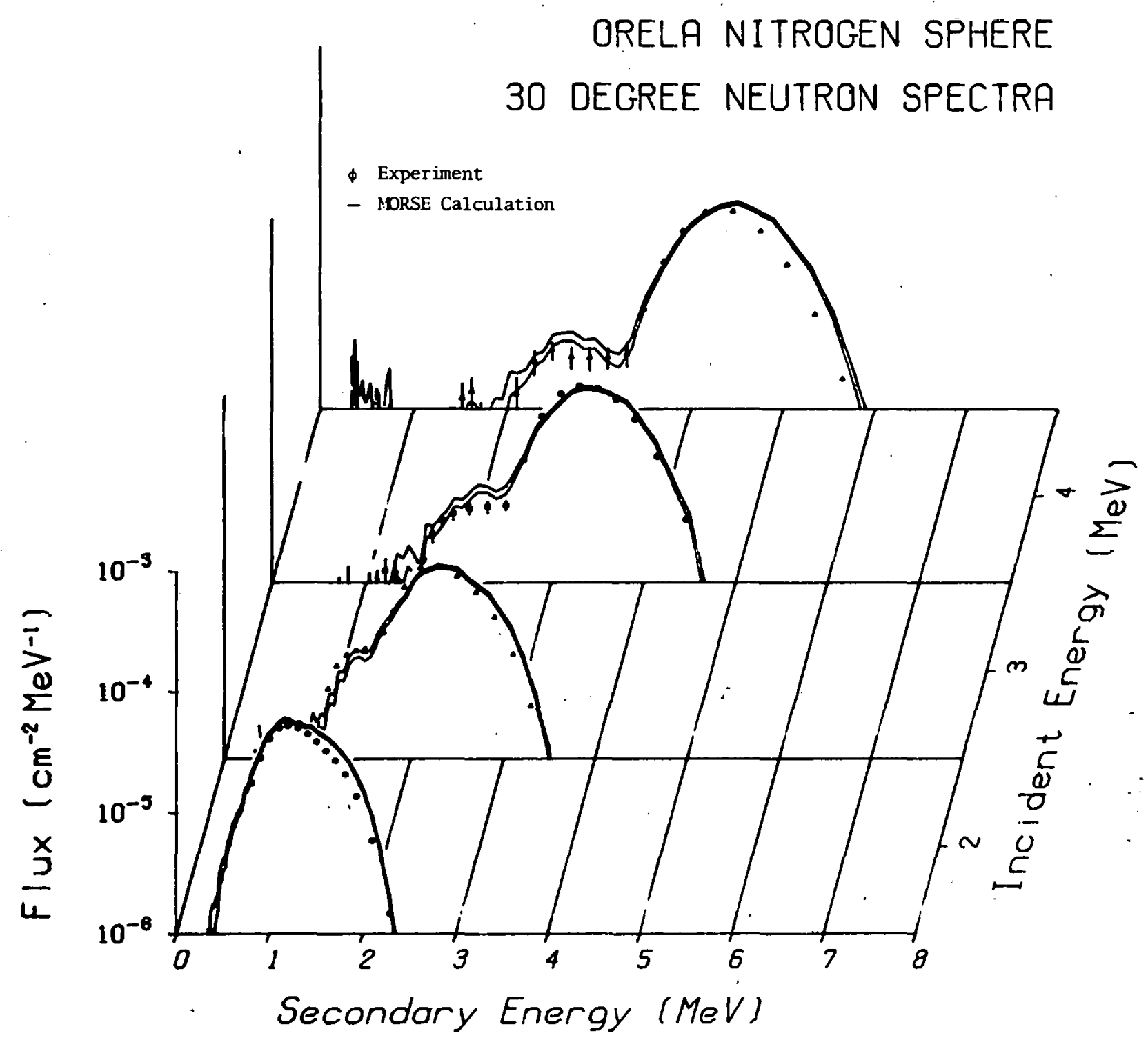

Fig. 21. ORNL Sphere Secondary Neutron Spectra at 30 deg Compared with Calculations Using ENDF/B-IV Nitrogen Data. 


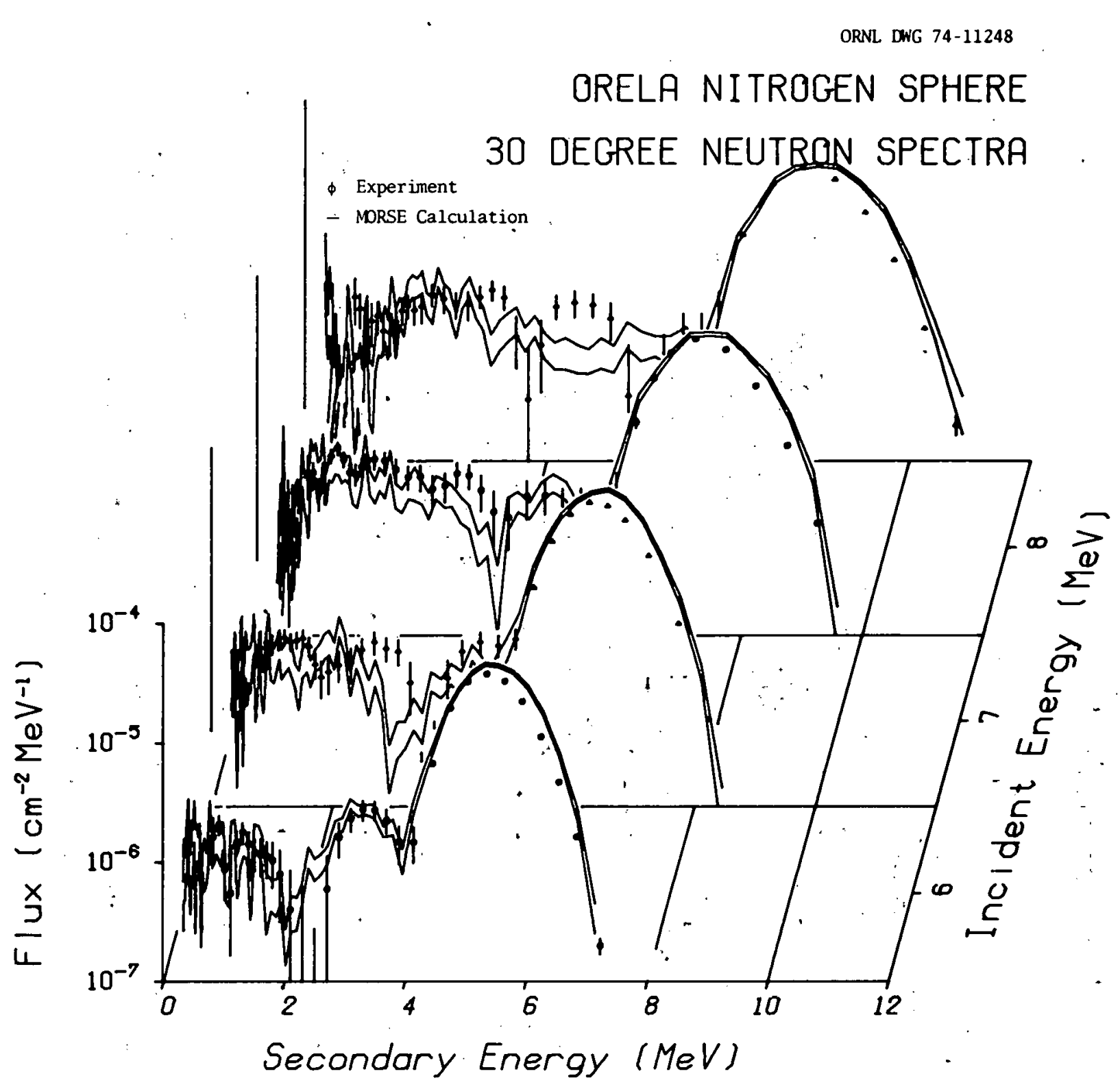

Fig. 22. ORNL Sphere Secondary Neutron Spectra at 30 deg Compared with Calculations Using ENDF/B-IV Nitrogen Data. 
ORNL DWG 74-11249

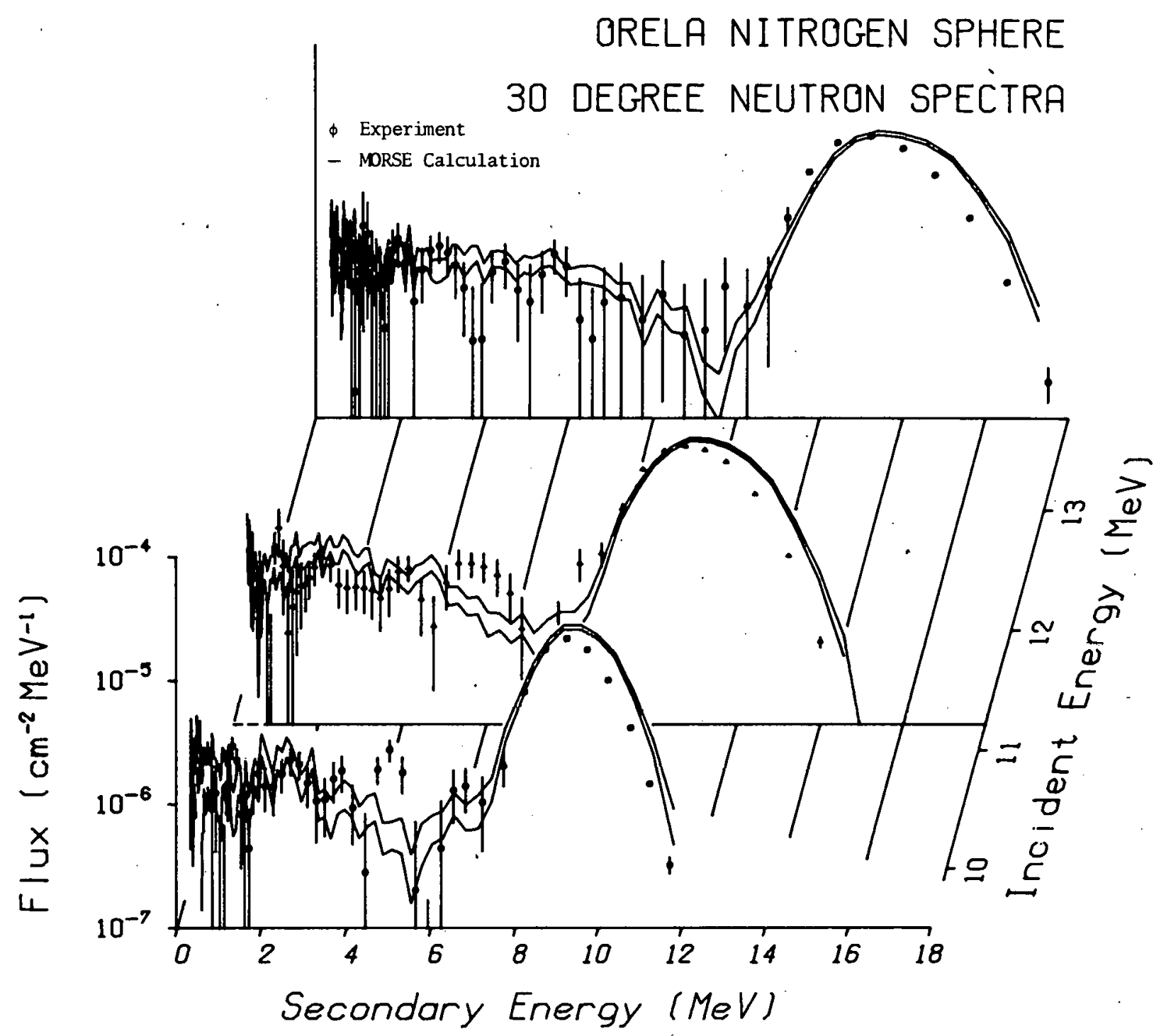

Fig. 23. ORNL Sphere Secondary Neutron Spectra at 30 deg Cumpared with Calculations Using ENDF/B-IV Nitrogen Data. 


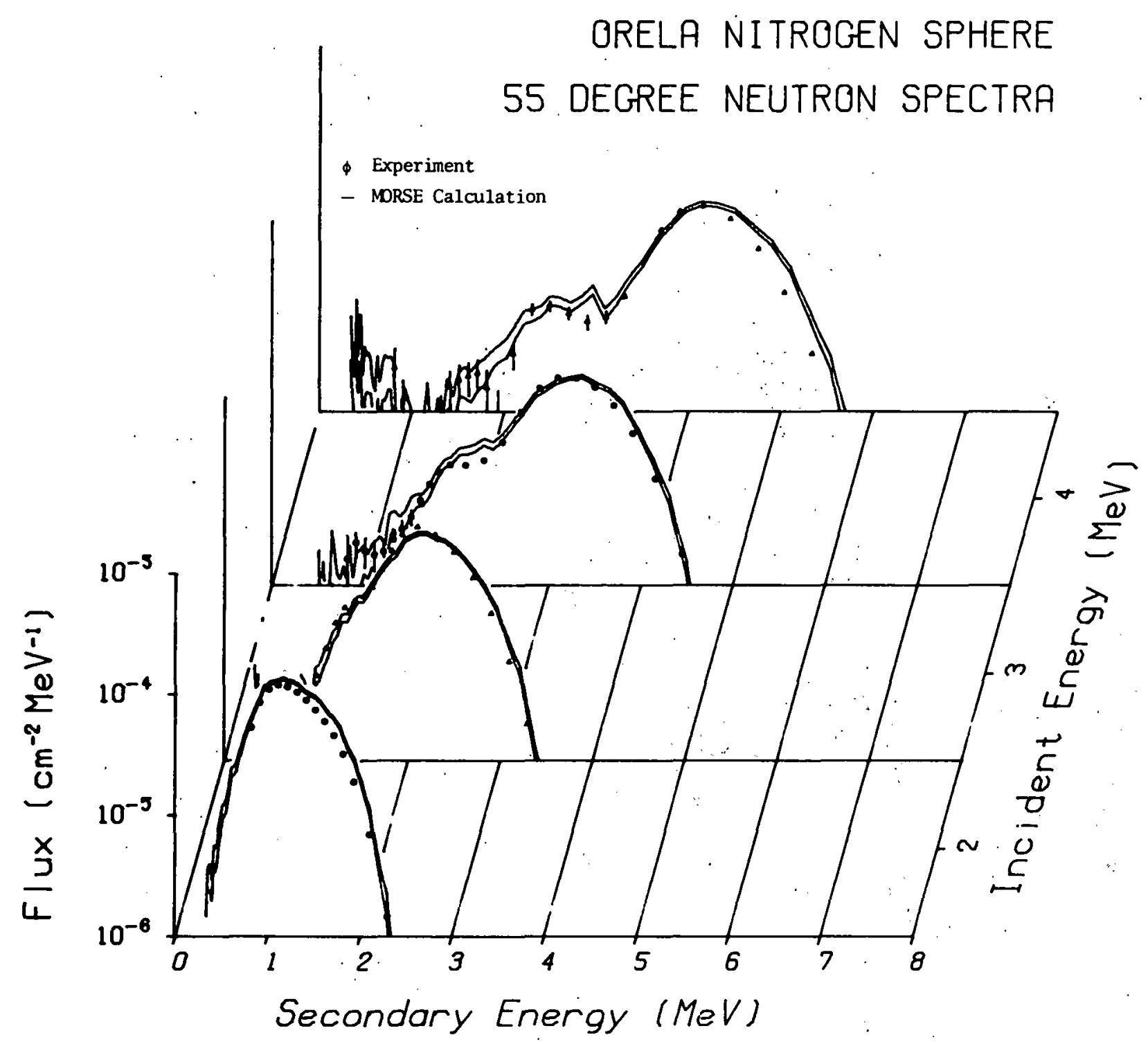

Fig. 24. ORNL Sphere Secondary Neutron Spectra at 55 deg Compared with Calculations Using ENDF/B-IV Nitrogen Data. 


\section{ORELA NITROGEN SPHERE 55 DEGREE NEUTRON SPECTRA}

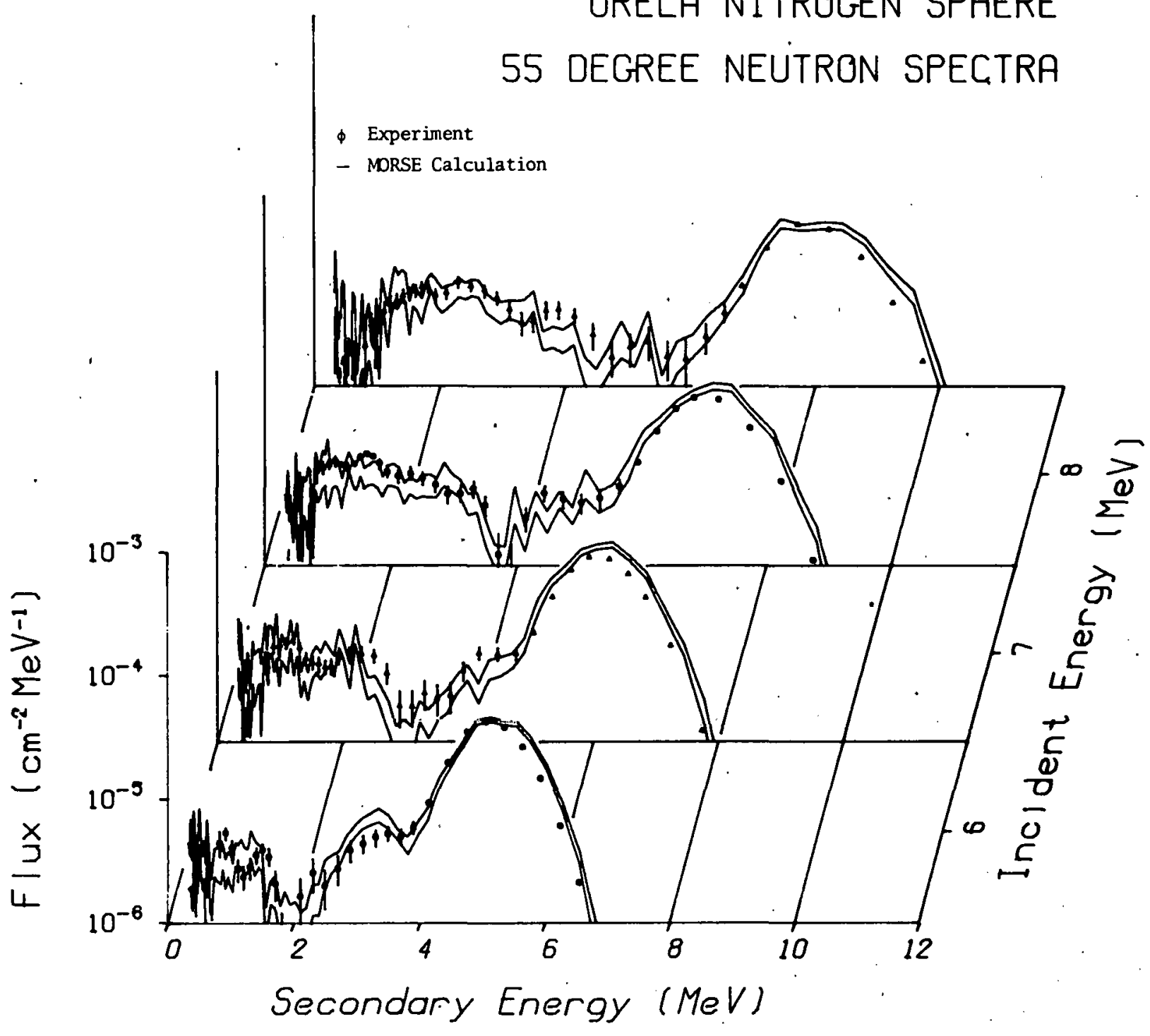

Fig. 25. ORNL Sphere Secondary Neutron Spectra at 55 deg Compared with Calculations Using ENDF/B-IV Nitrogen Data. 


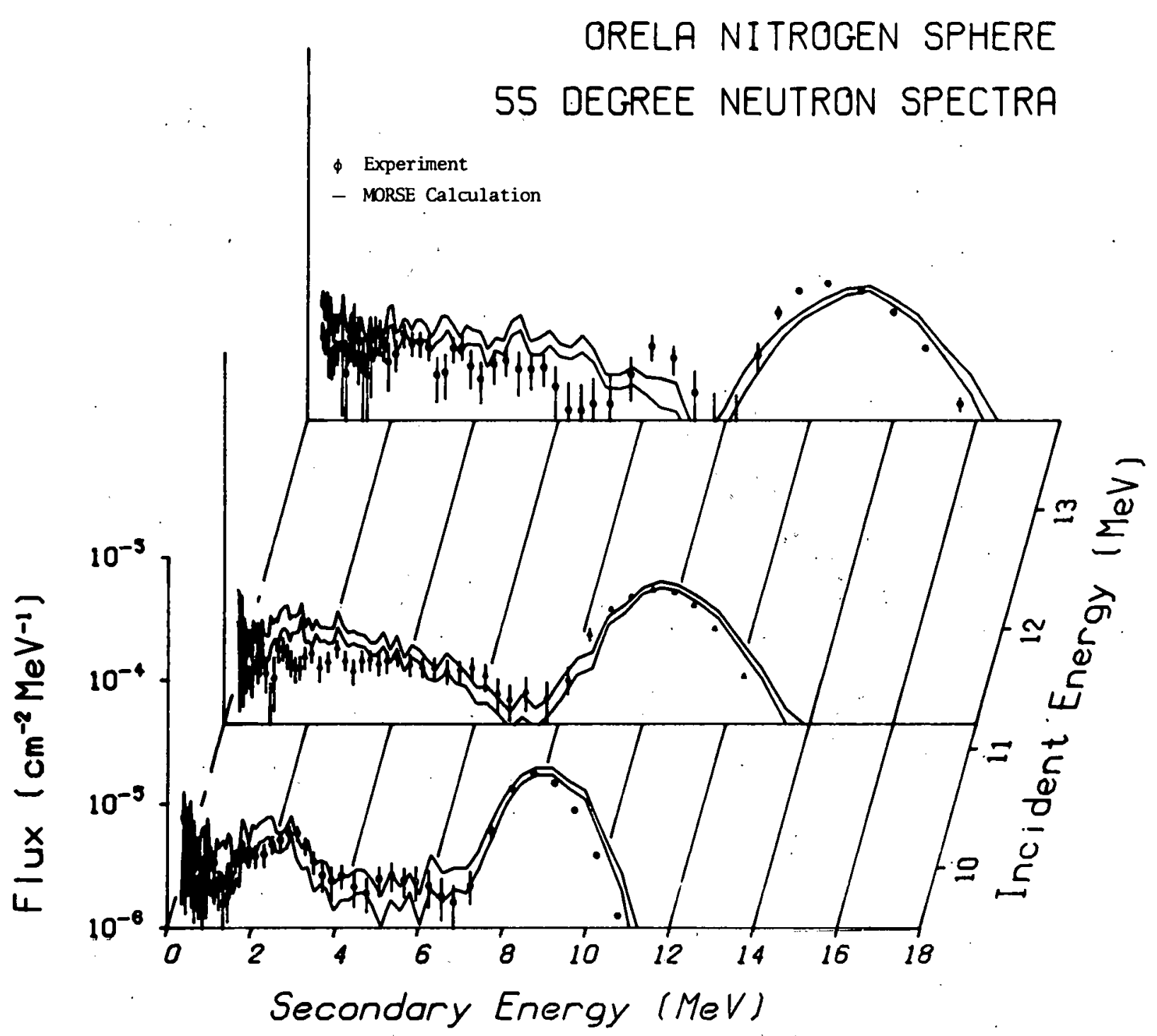

Fig. 26. ORNL Sphere Secondary Neutron Spectra at 55 deg Compared with Calculations Using ENDF/B-IV Nitrogen Data. 


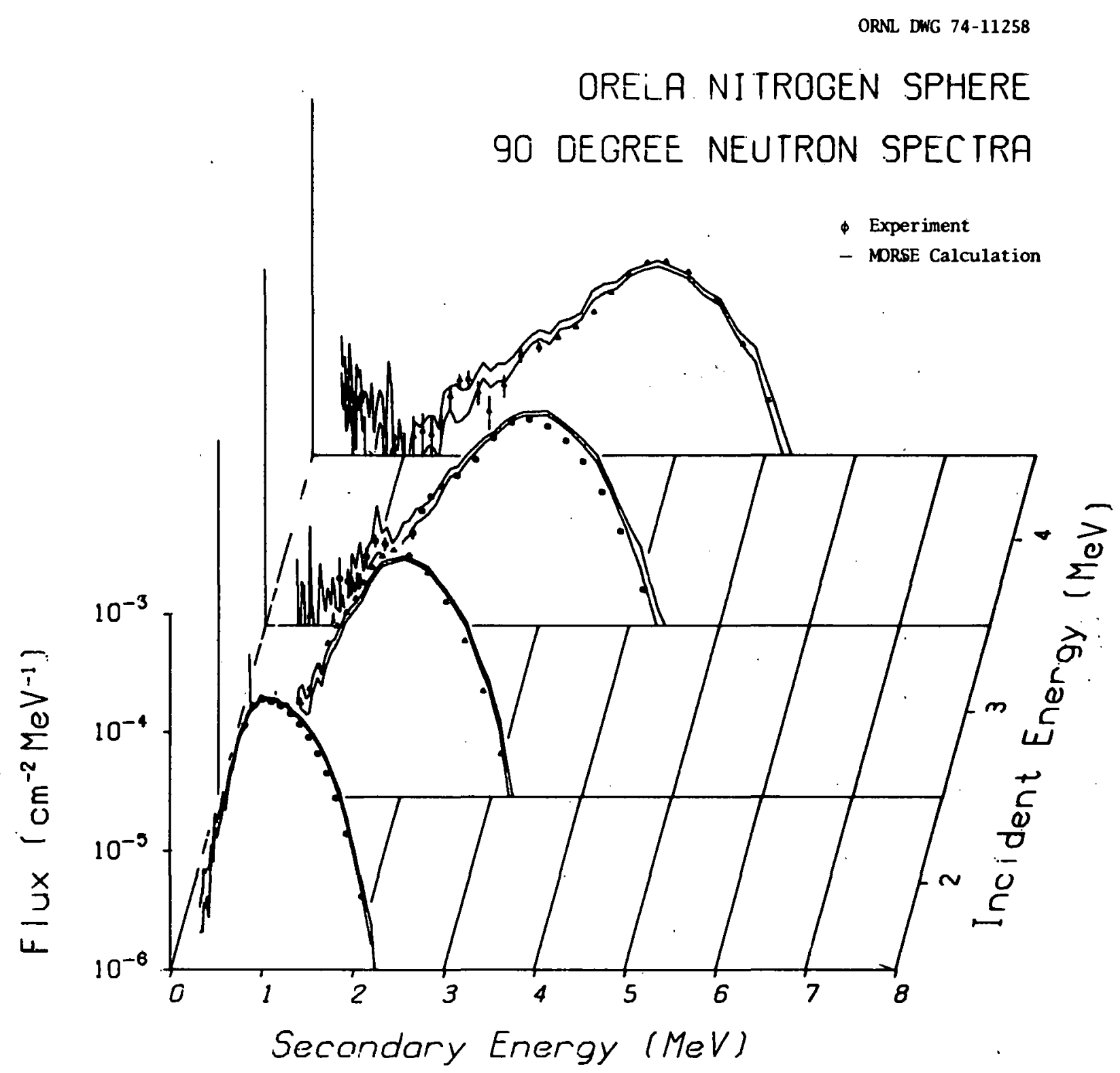

Fig. 27. ORNL Sphere Secondary Neutron Spectra at 90 deg Compared with Calculations Using ENDF/B-IV Nitrogen Data. 
ORNL DWG 74-11257

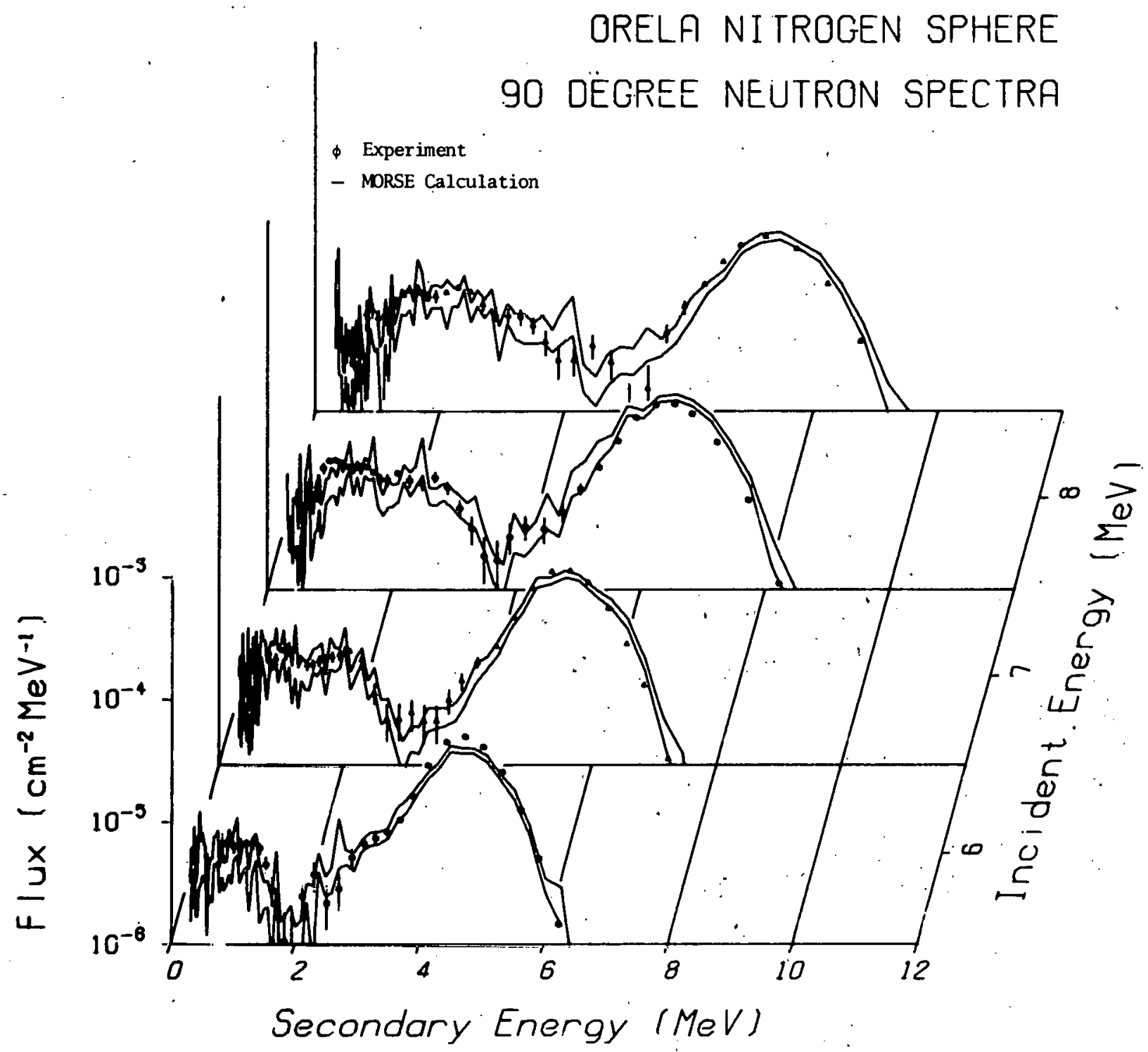

Fig. 28. ORNL Sphere Secondary Neutron Spectra at 90 deg Compared with Calculations Using ENDF/B-IV Nitrogen Data. 


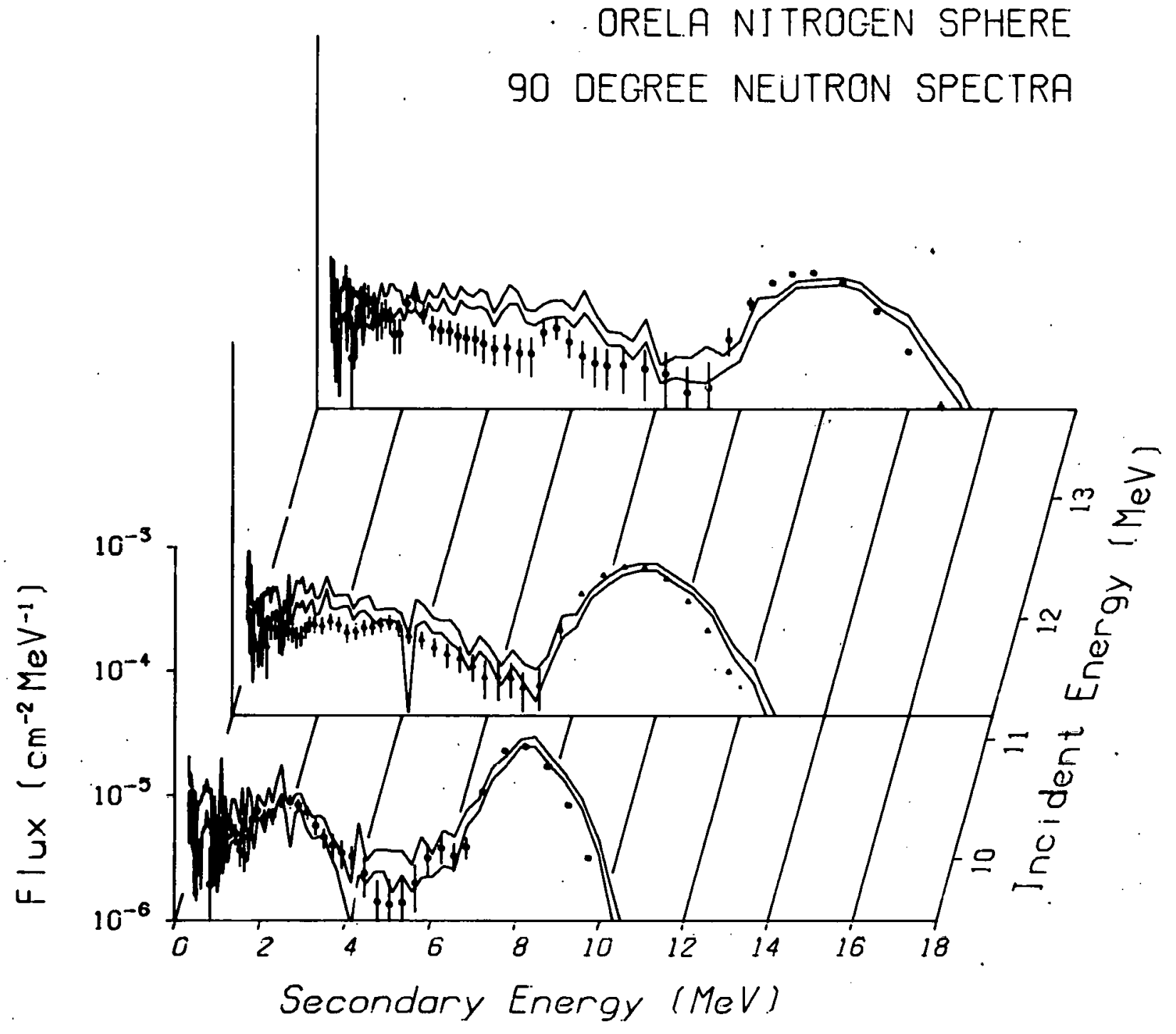

Fig. 29. ORNL Sphere Secondary Neutron Spectra at 90 deg Compared with Calculations Using ENDF/B-IV Nitrogen Data. 


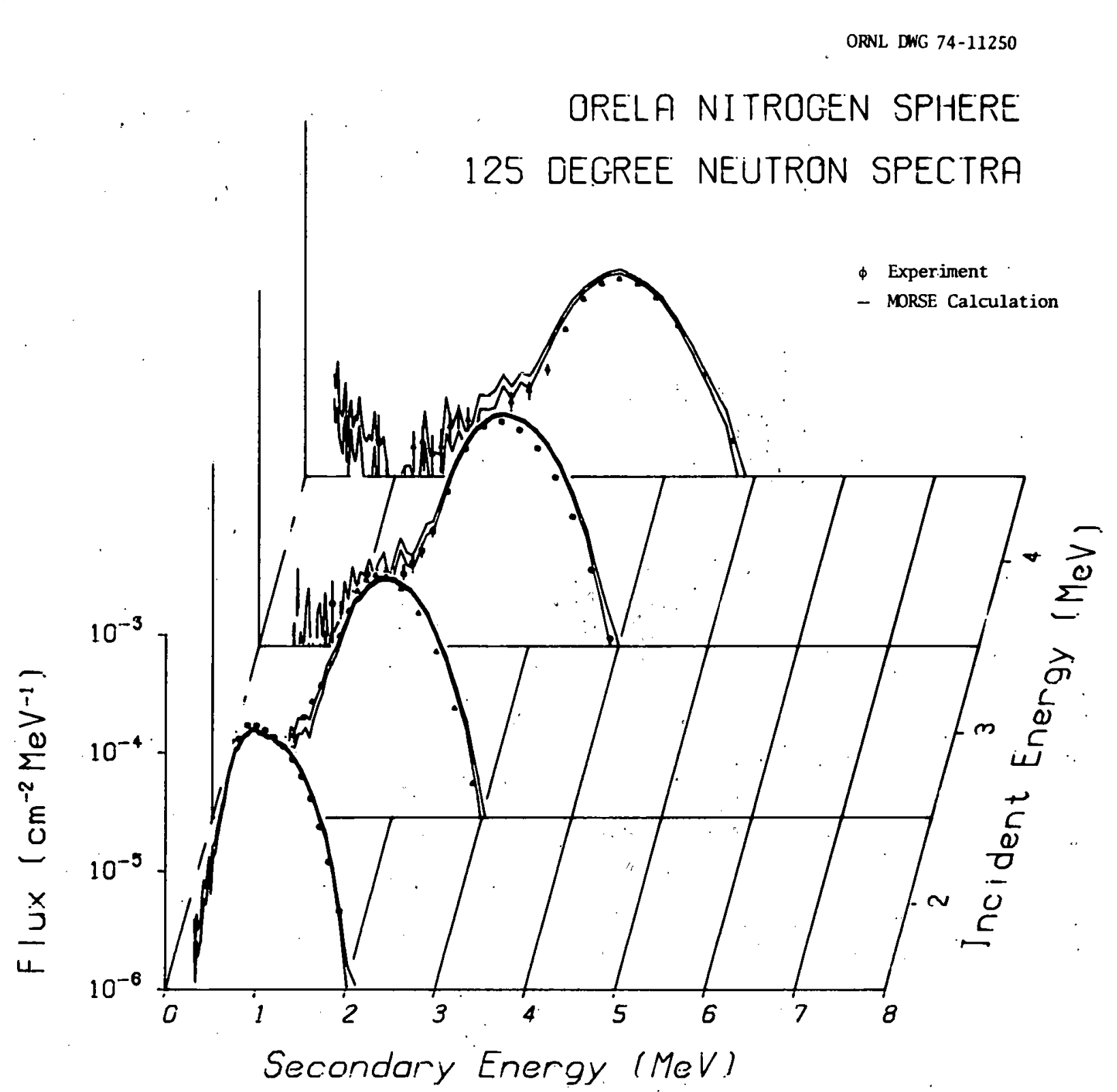

Fig. 30. ORNL Sphere Secondary Neutron Spectra at 125 deg Compared with Calrulations Using ENDF/B-IV Nitrogen Data. 


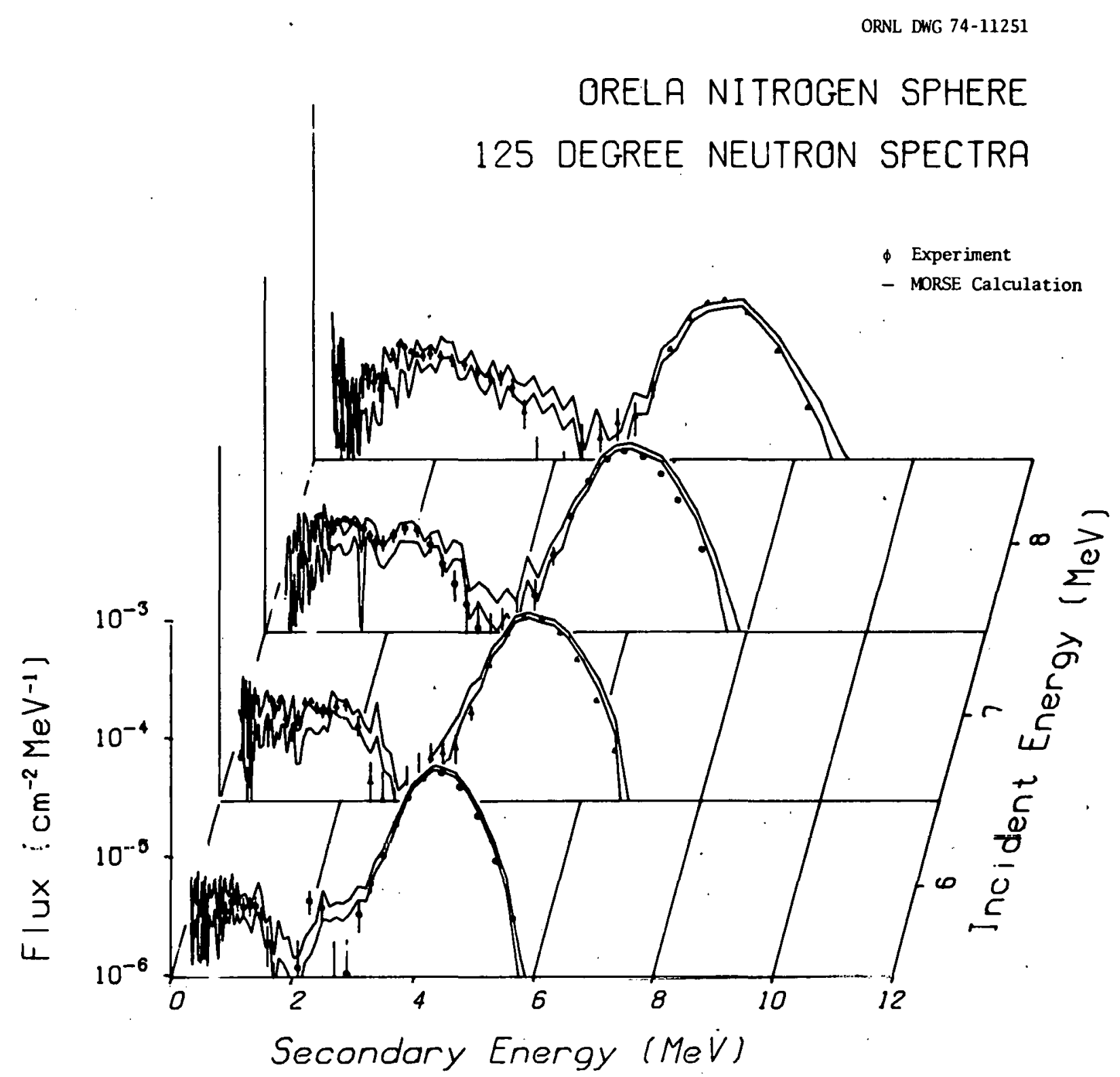

Fig. 31. ORNL Sphere Secondary Neutron Spectra at 125 deg Compared with Calculations Using ENDF/B-IV Nitrogen Data. 


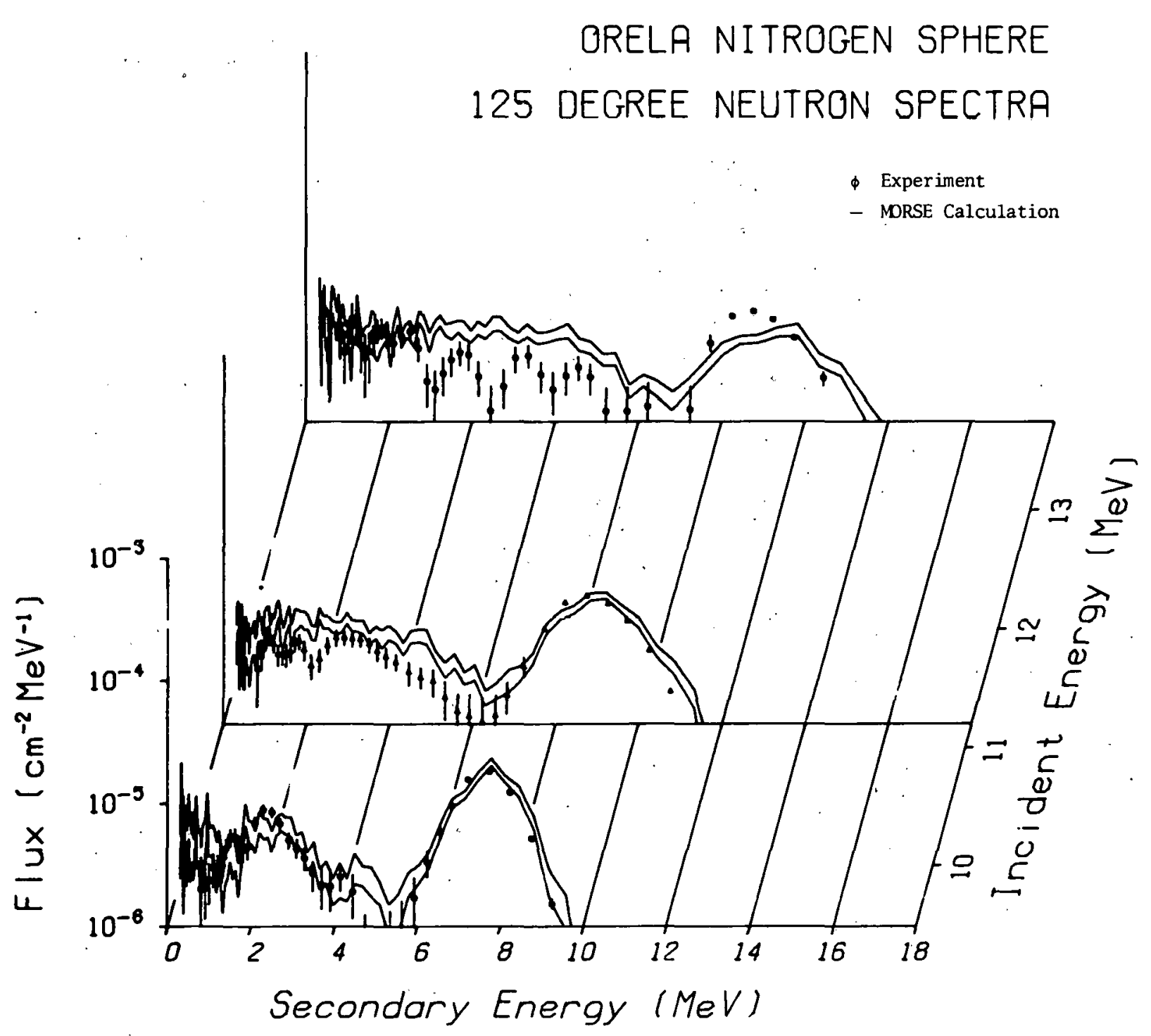

Fig. 32. ORNL Sphere Secondary Neutron Spectra at 125 deg Compared with Calculations Using ENDF/B-IV Nitrogen Data. 


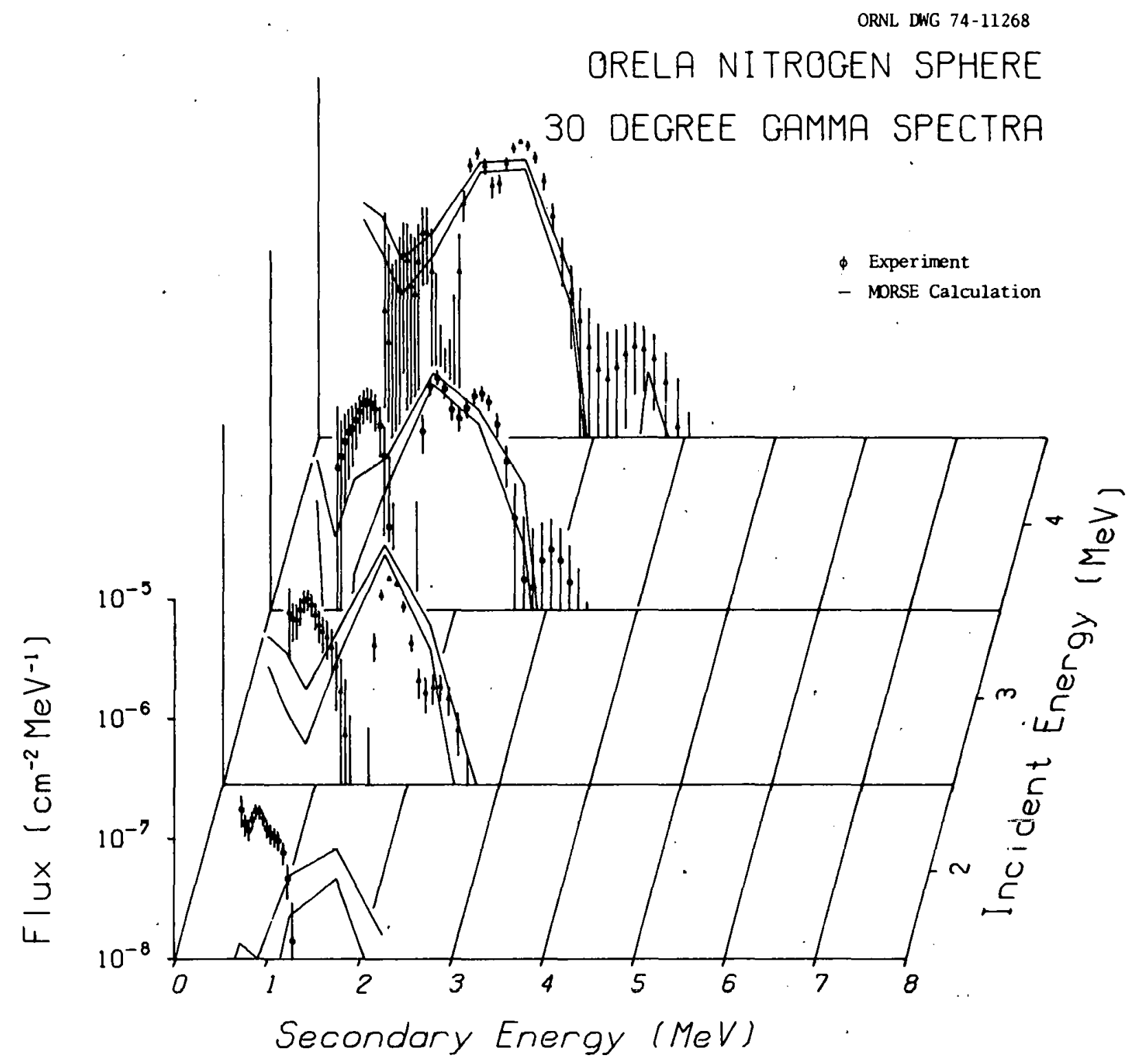

Fig. 33. ORNL Sphere Secondary Gamma-Ray Spectra at 30 deg Compared with Calculations Using ENDF/B-IV Nitrogen Data. 


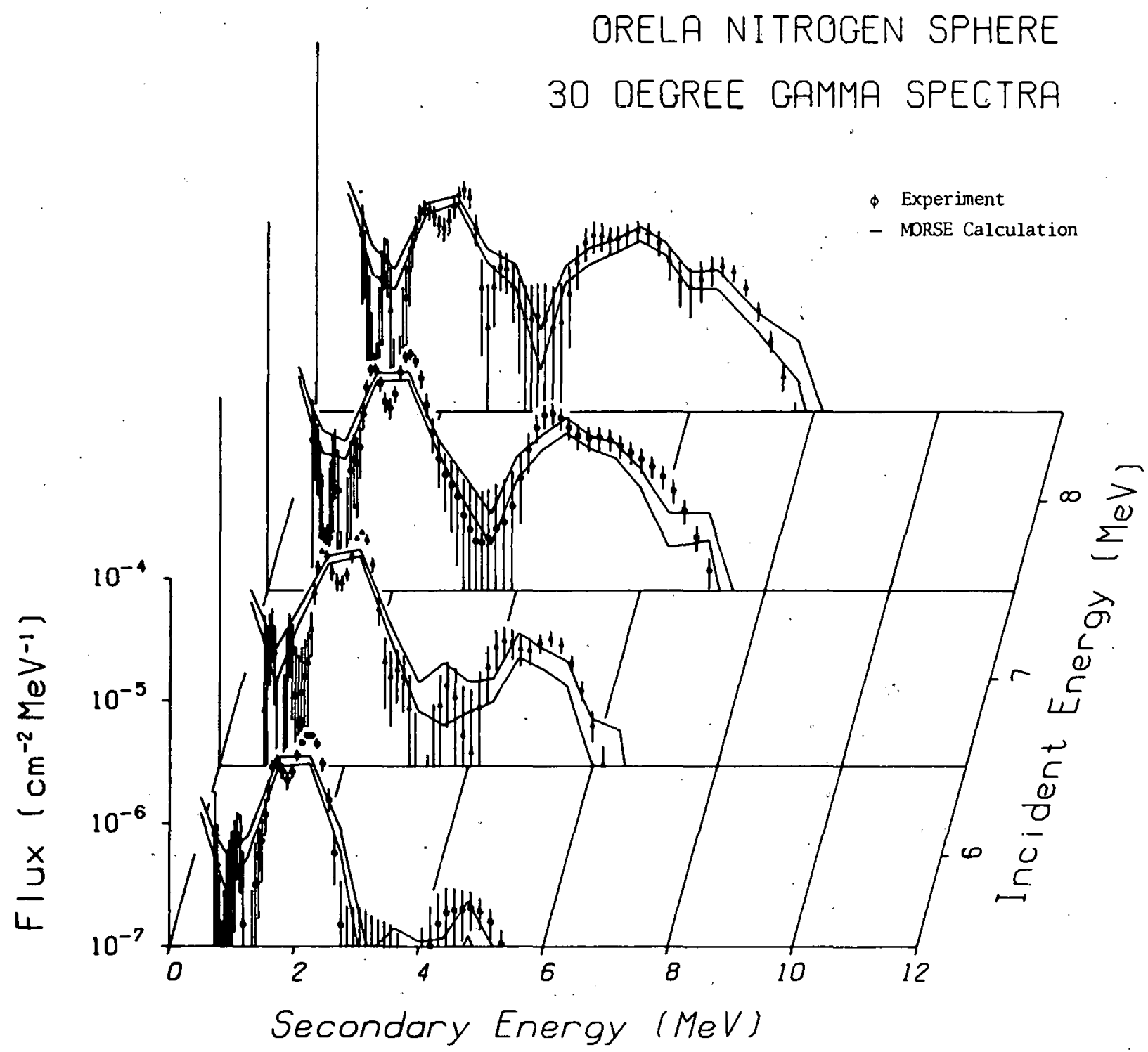

Fig. 34. ORNL Sphere Secondary Gamma-Ray Spectra at. 30 deg Compared with Calculations Using ENDF/B-IV Nitrogen Data. 
ORNL DWG 74-11269

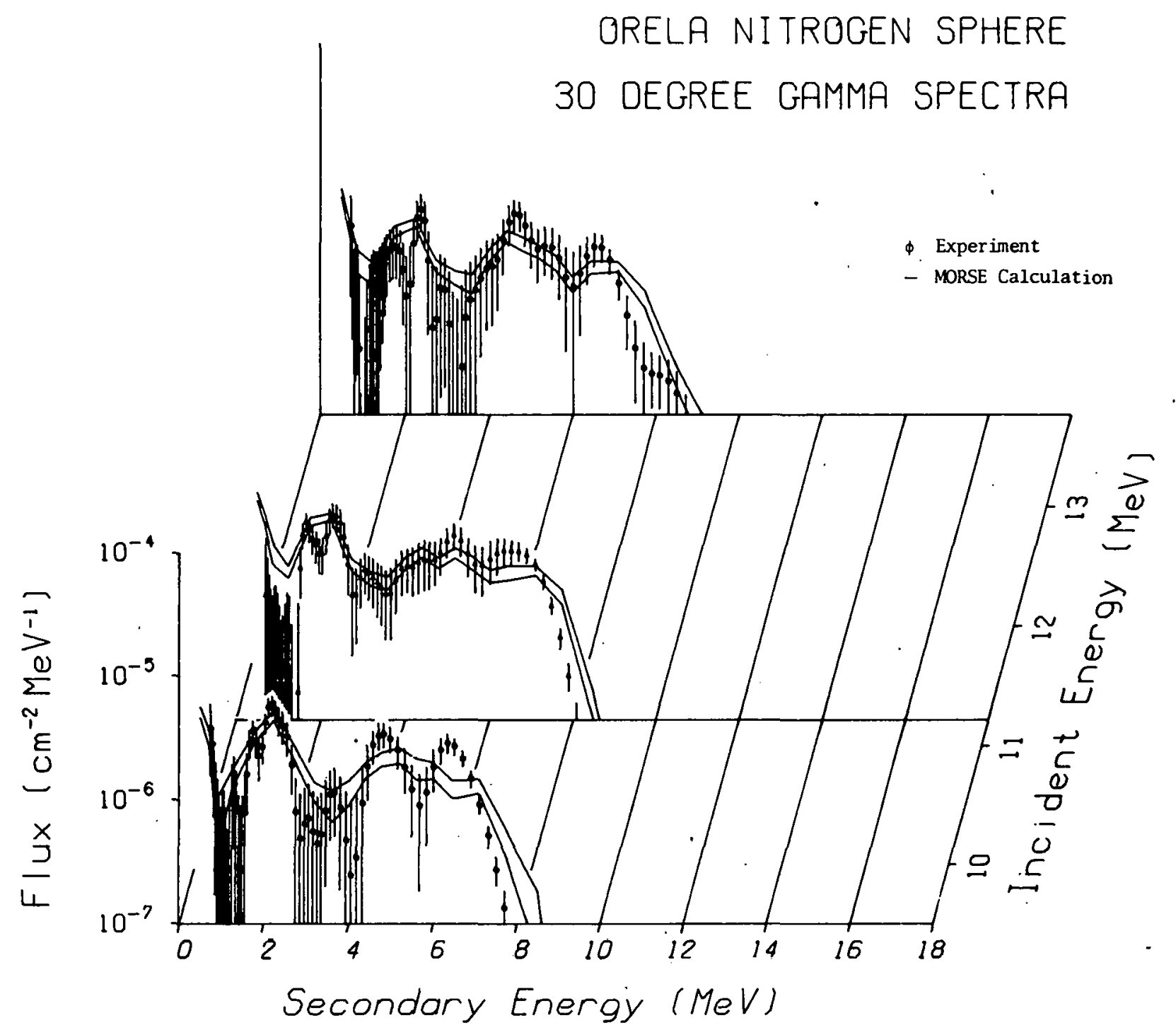

Fig. 35. ORNL Sphere Secondary Gamma-Ray Spectra at 30 deg Compared with Calculations Using ENDF/B-IV Nitrogen Data. 
ORNL DWG 74-11260

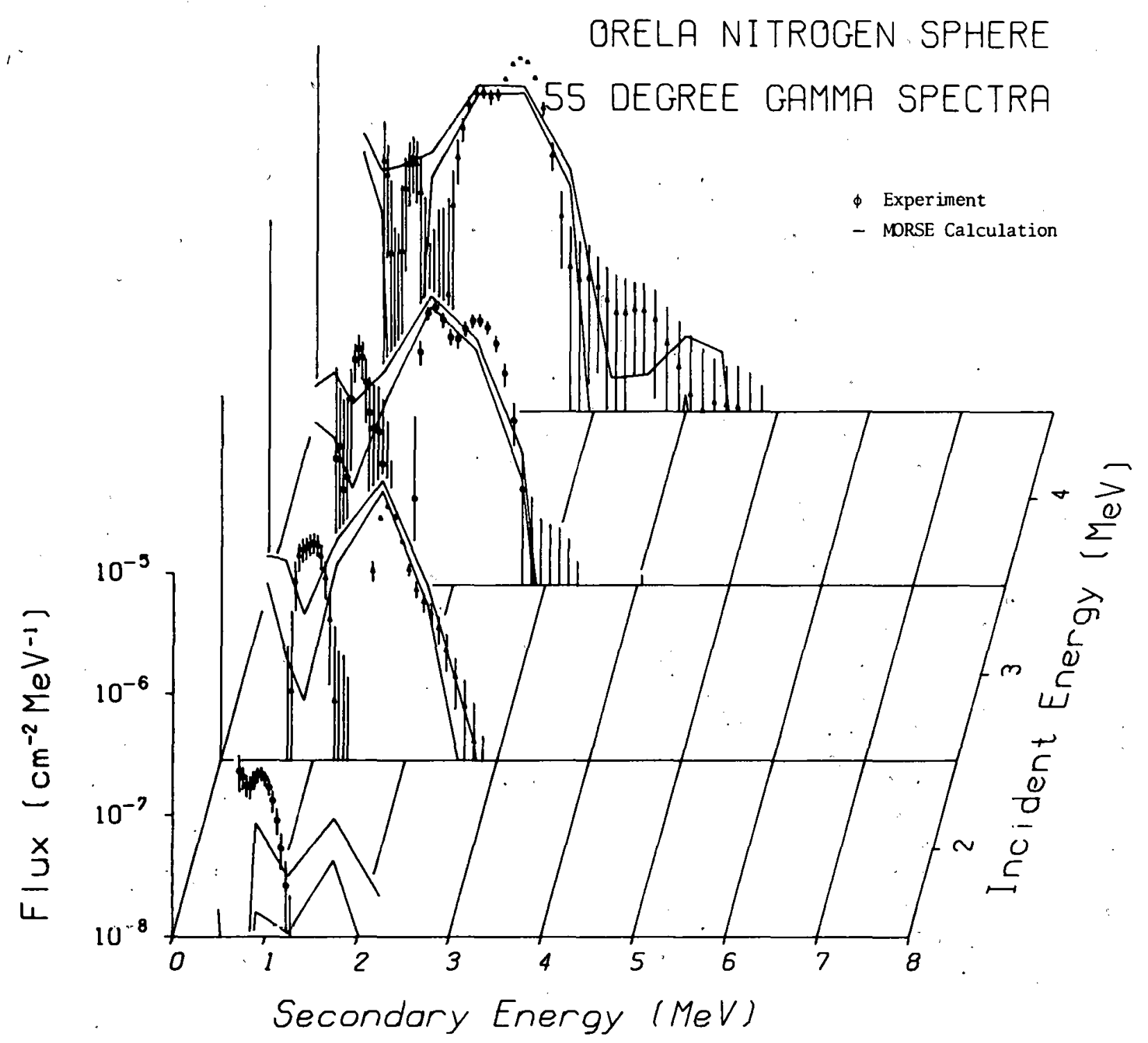

Fig. 36. ORNL Sphere Secondary Gamma-Ray Spectra at 55 deg Compared with Calculations Using ENDF/B-IV Nitrogen Data. 
ORNI. DWG 74-11259

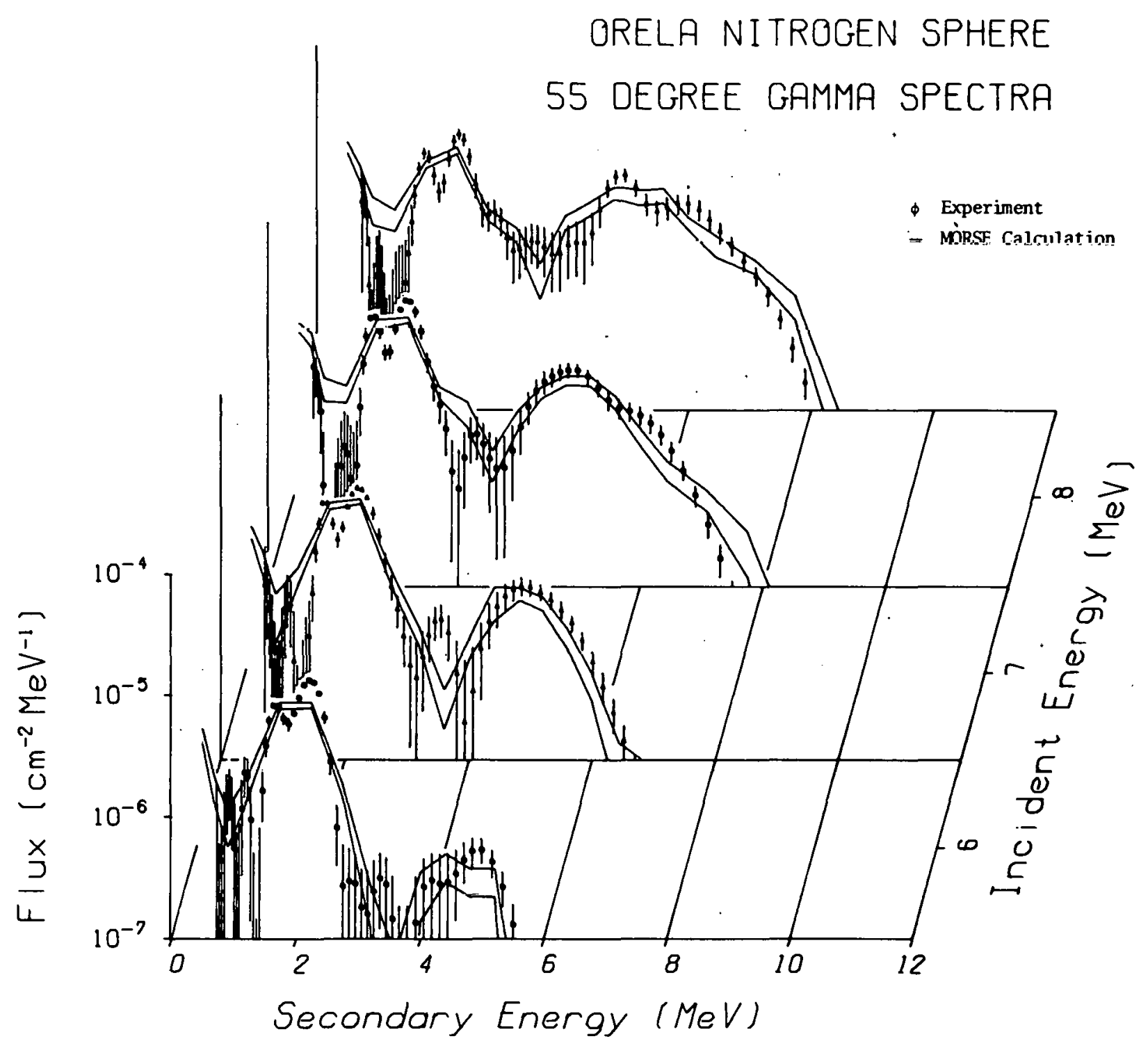

Fig. 37. ORNL Sphere Secondary Gamma-Ray Spectra at $55 \mathrm{deg}$ Compared with Calculations Using ENDF/B-IV Nitrogen Data. 
ORNL DWG 74-11245

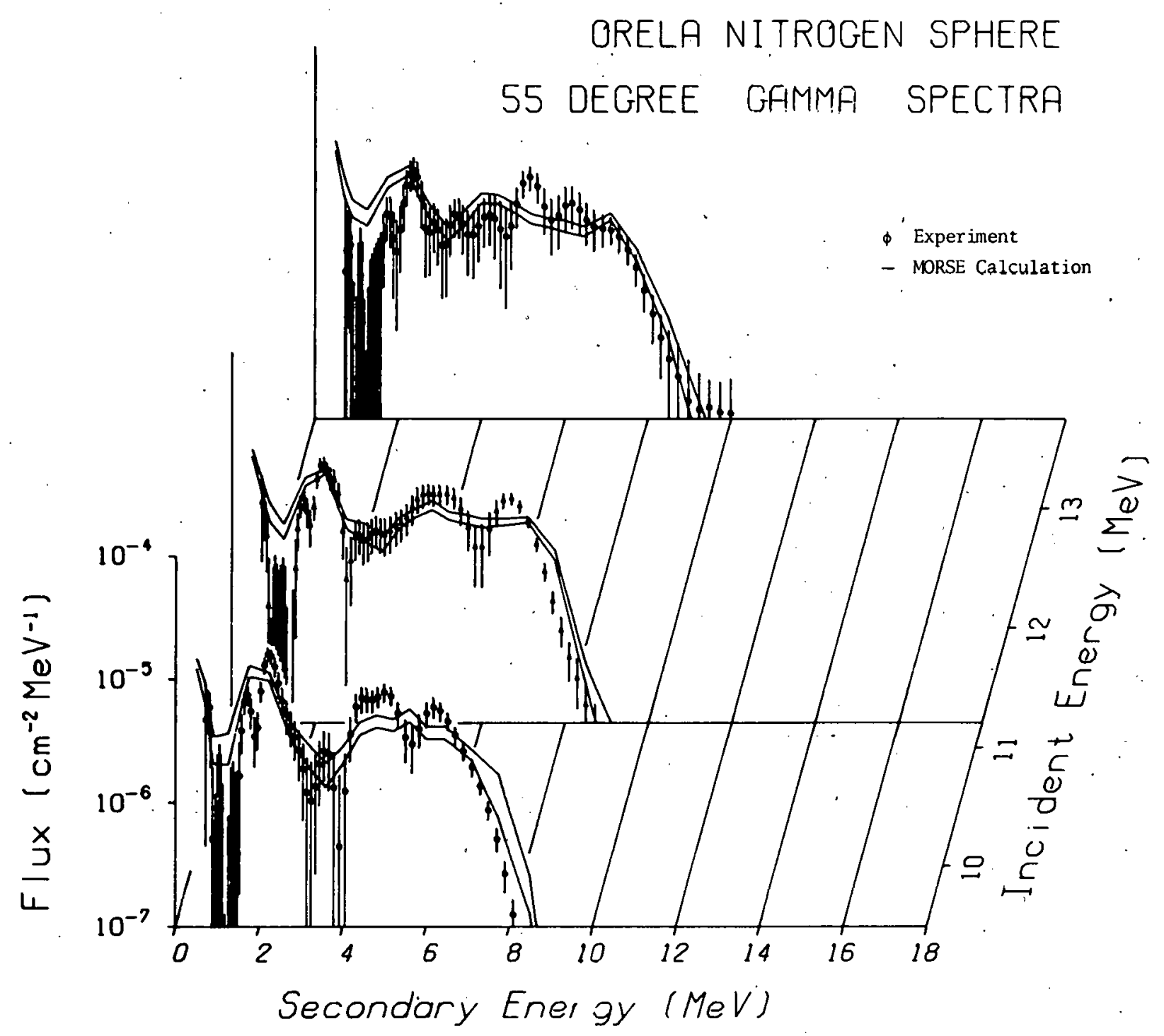

Fig. 38. ORNL Sphere Secondary Gamma-Ray Spectra at $55 \mathrm{deg}$ Compared with Calculations Using ENDF/B-IV Nitrogen Data. 
ORNL DWG 74-11263

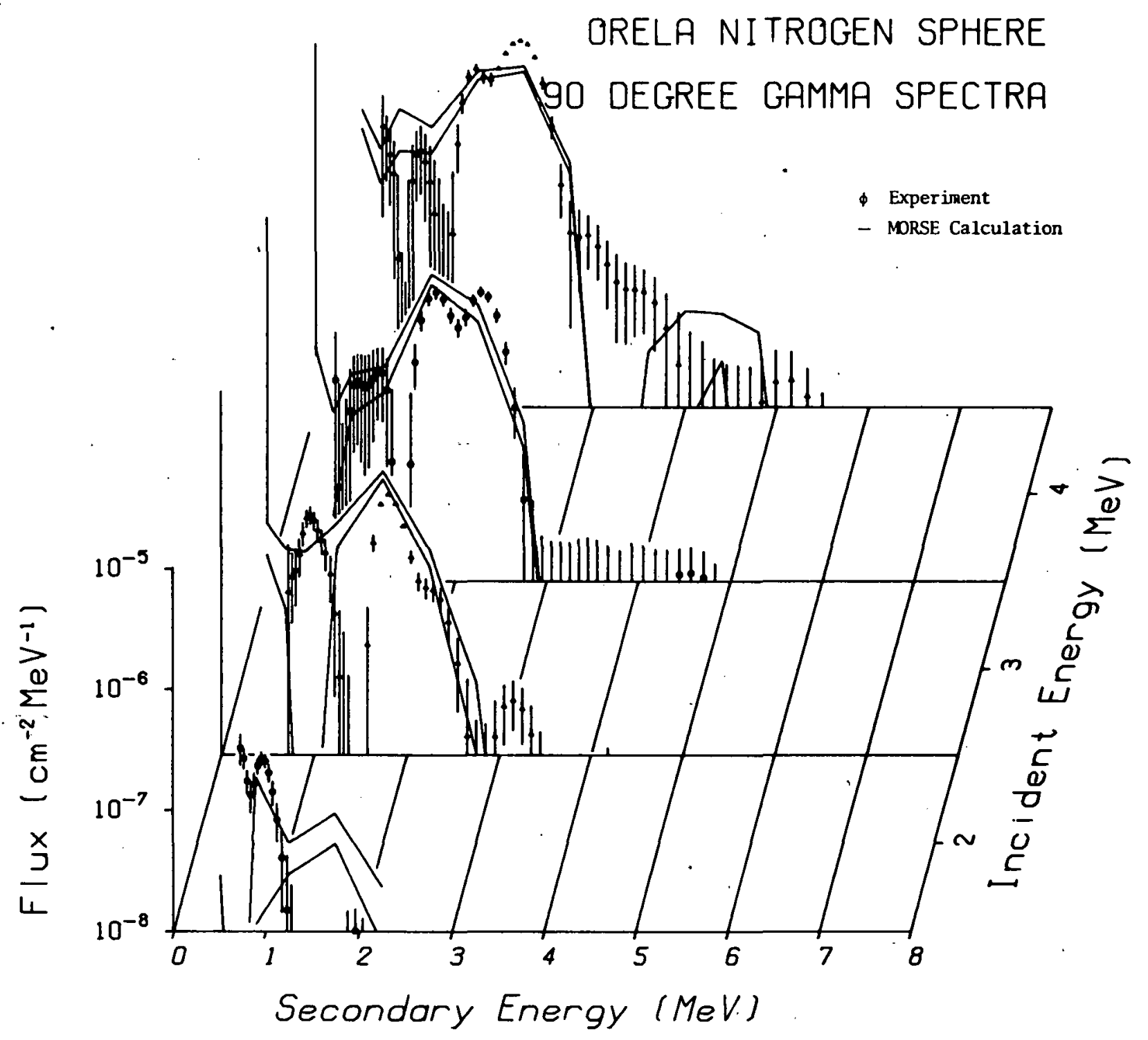

Fig. 39. ORNL Sphere Secondary Gamma-Ray Spectra at 90 deg Compared with Calculations Using ENDF/B-IV Nitrogen Data. 


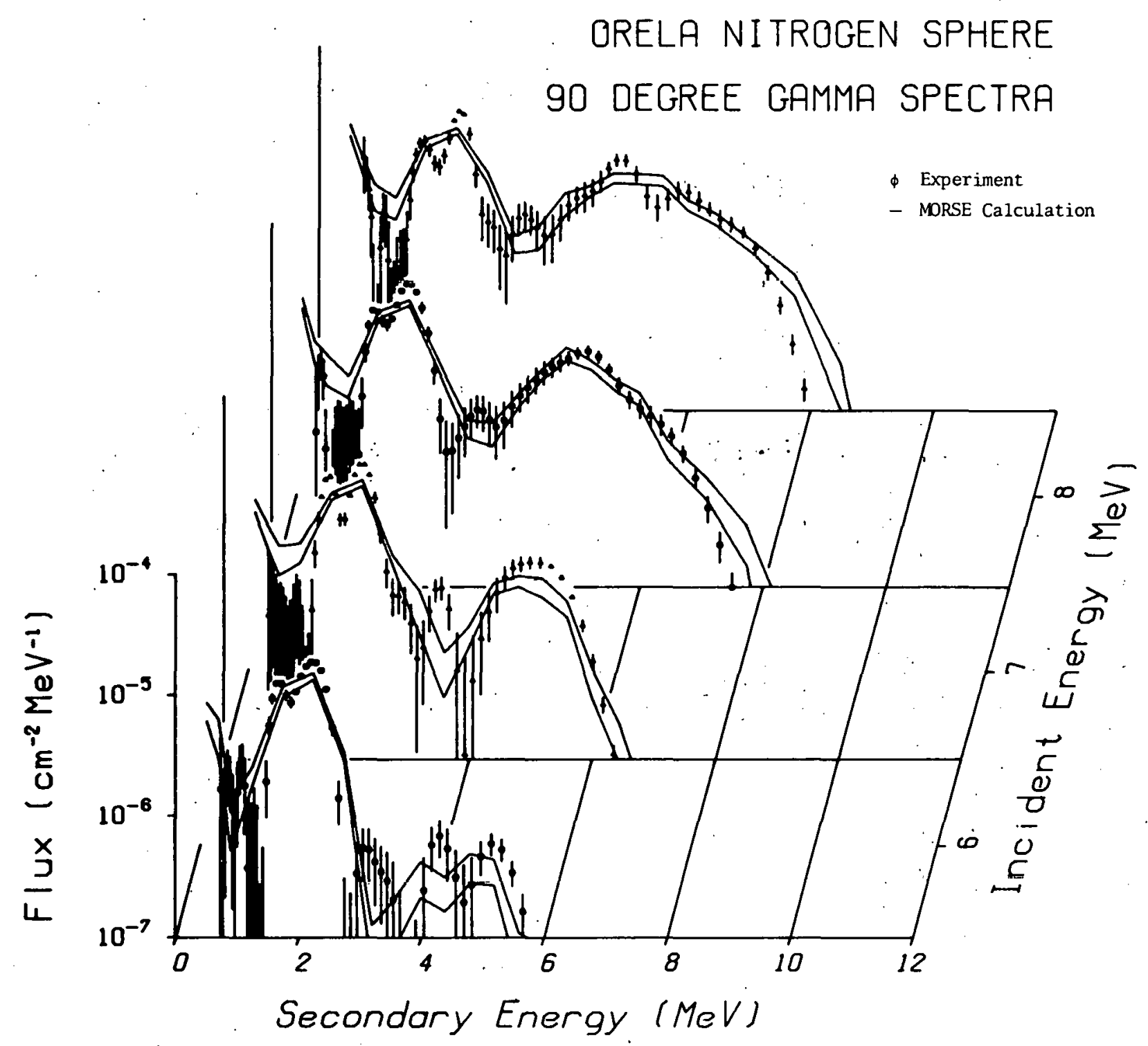

F1g. 40. ORNL Sphere Secondary Gamma-Ray Spectra at 90 deg Compared with Calculations Using ENDF/B-IV Nitrogen Data. 
ORNL DWG 74-11262

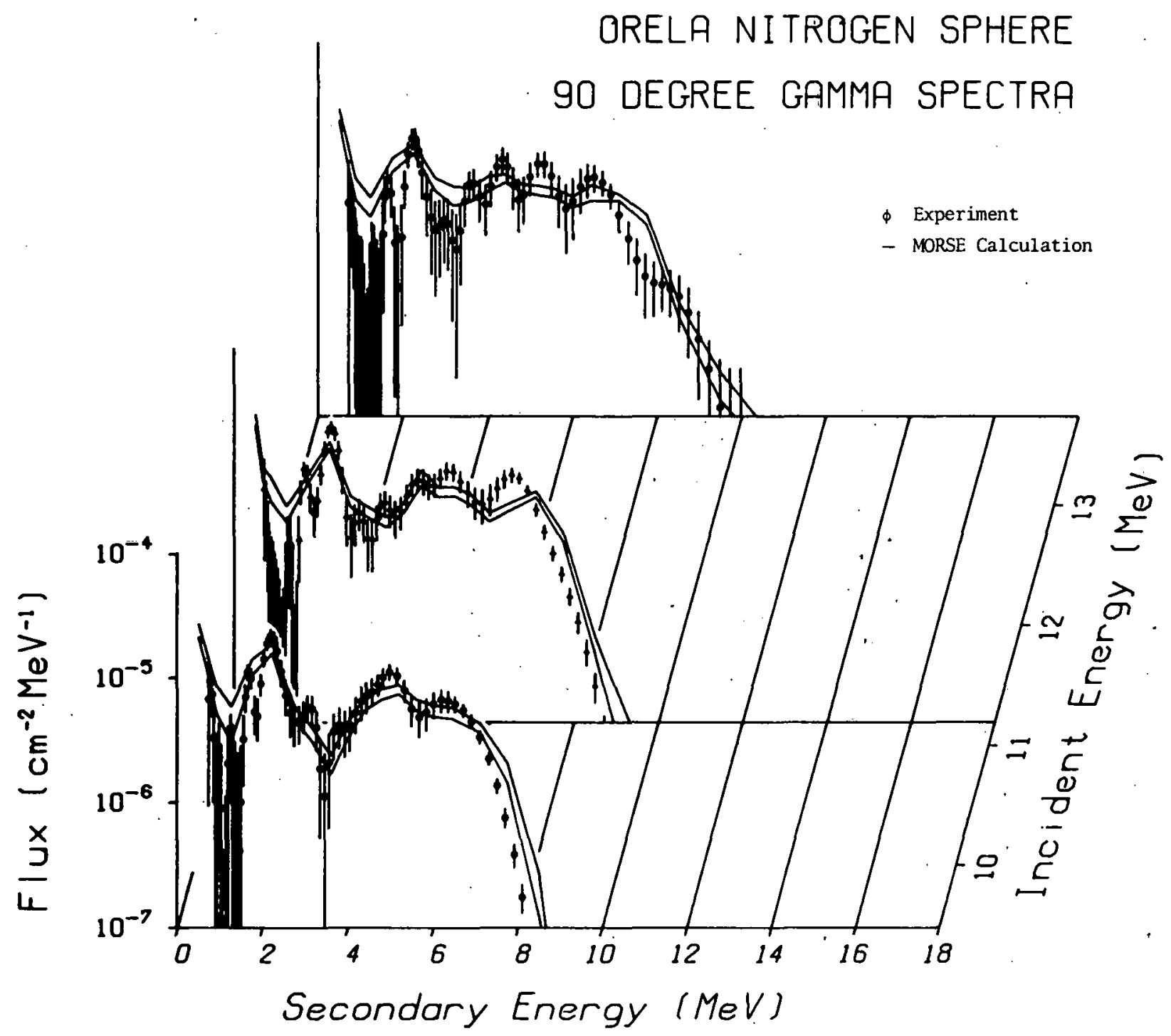

Fig. 41. ORNL Sphere Secondary Gamma-Ray Spectra at 90 deg Compared with Calculations Using ENDF/B-IV Nitrogen Data. 
ORNL DWG 74-11264

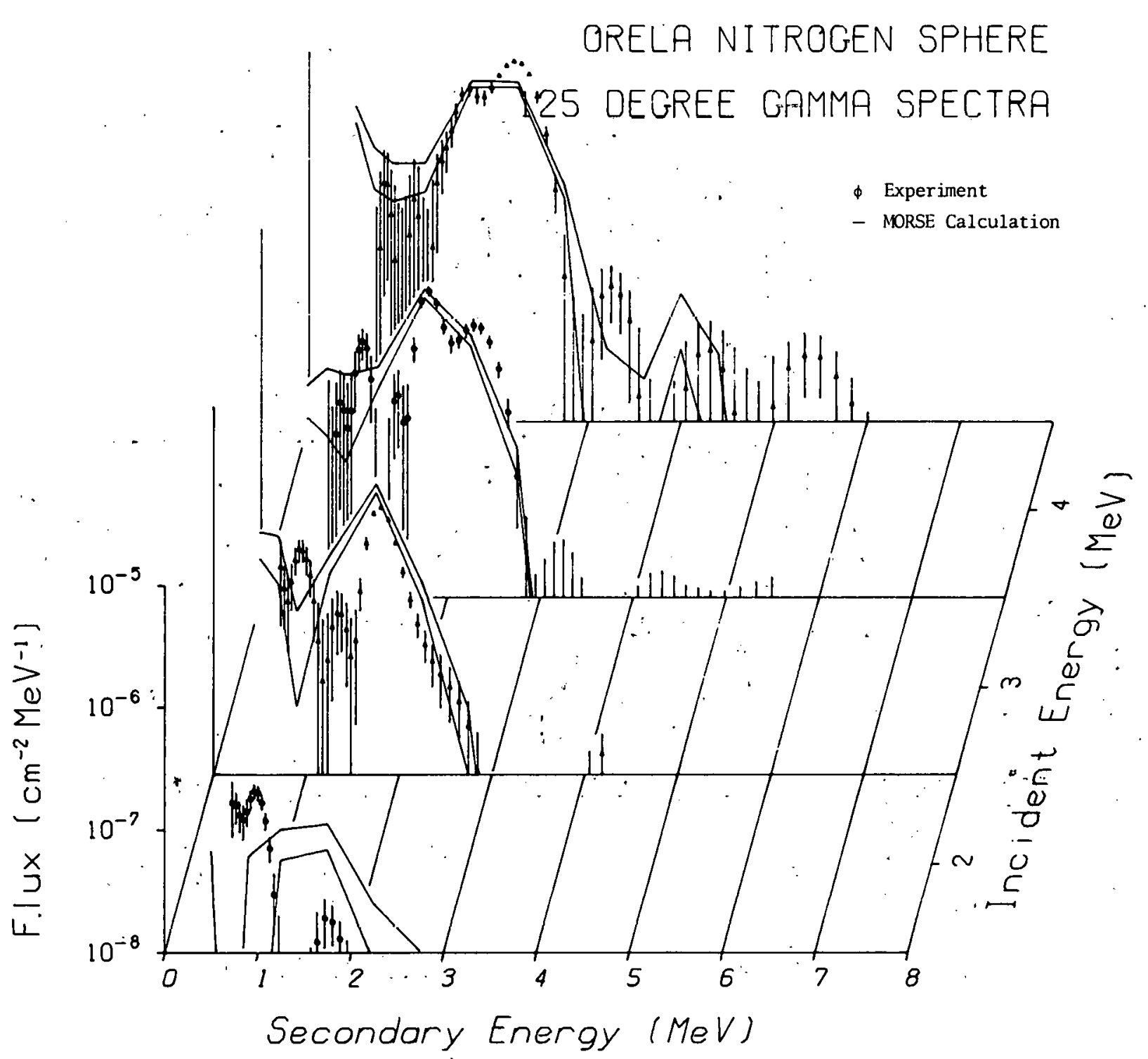

Fig. 42. . ORNL Sphere Secondary Gamma-Ray Spectra at 125 deg Compared with Calculations Using ENDF/B-IV, Nitrogen Data. 
ORNL DWG 74-11265

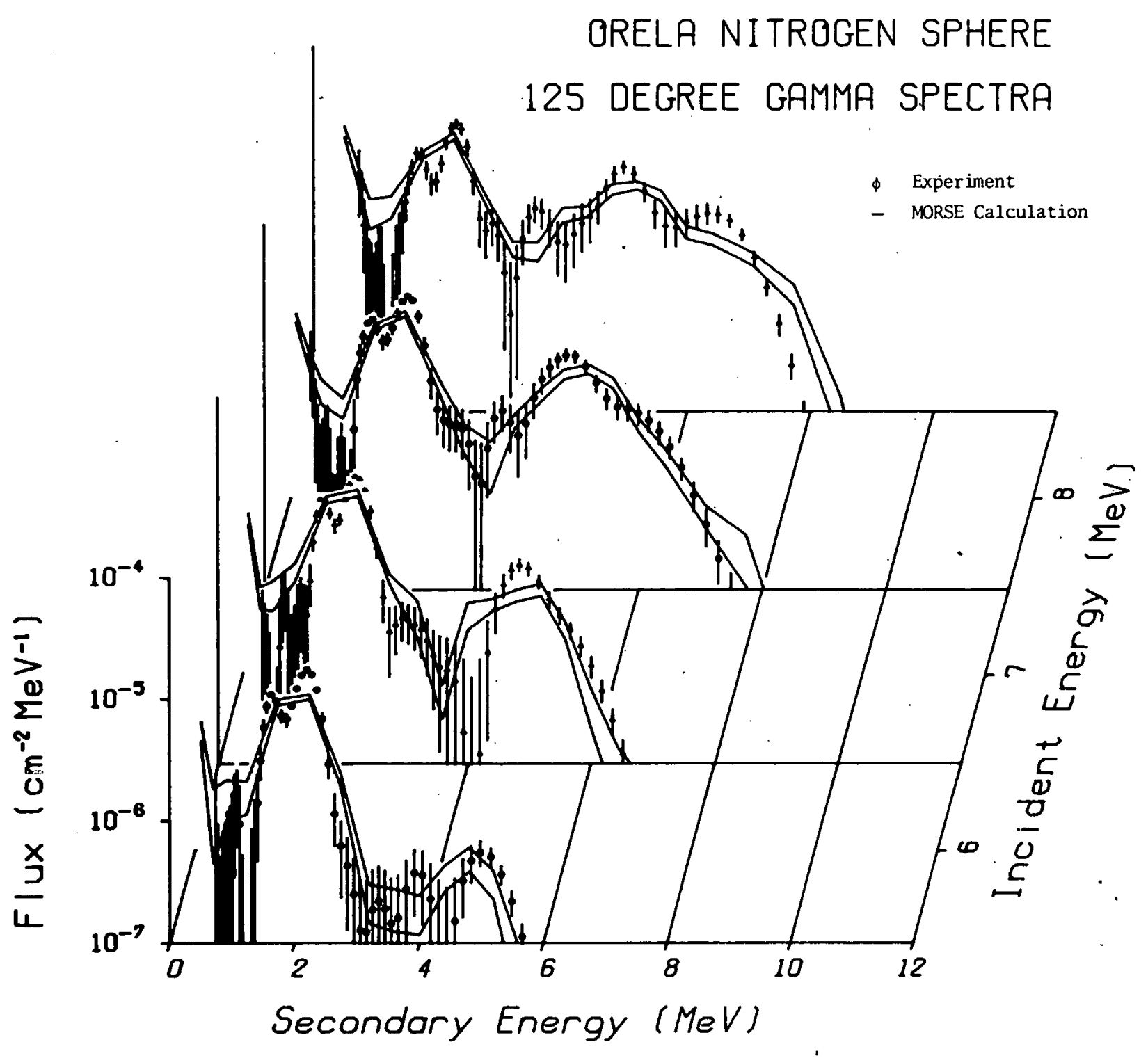

Fig. 43. ORNL Sphere Secondary Gamma-Ray Spectra at 125 deg Compared with Calculations Using ENDF/B-IV Nitrogen Data. 


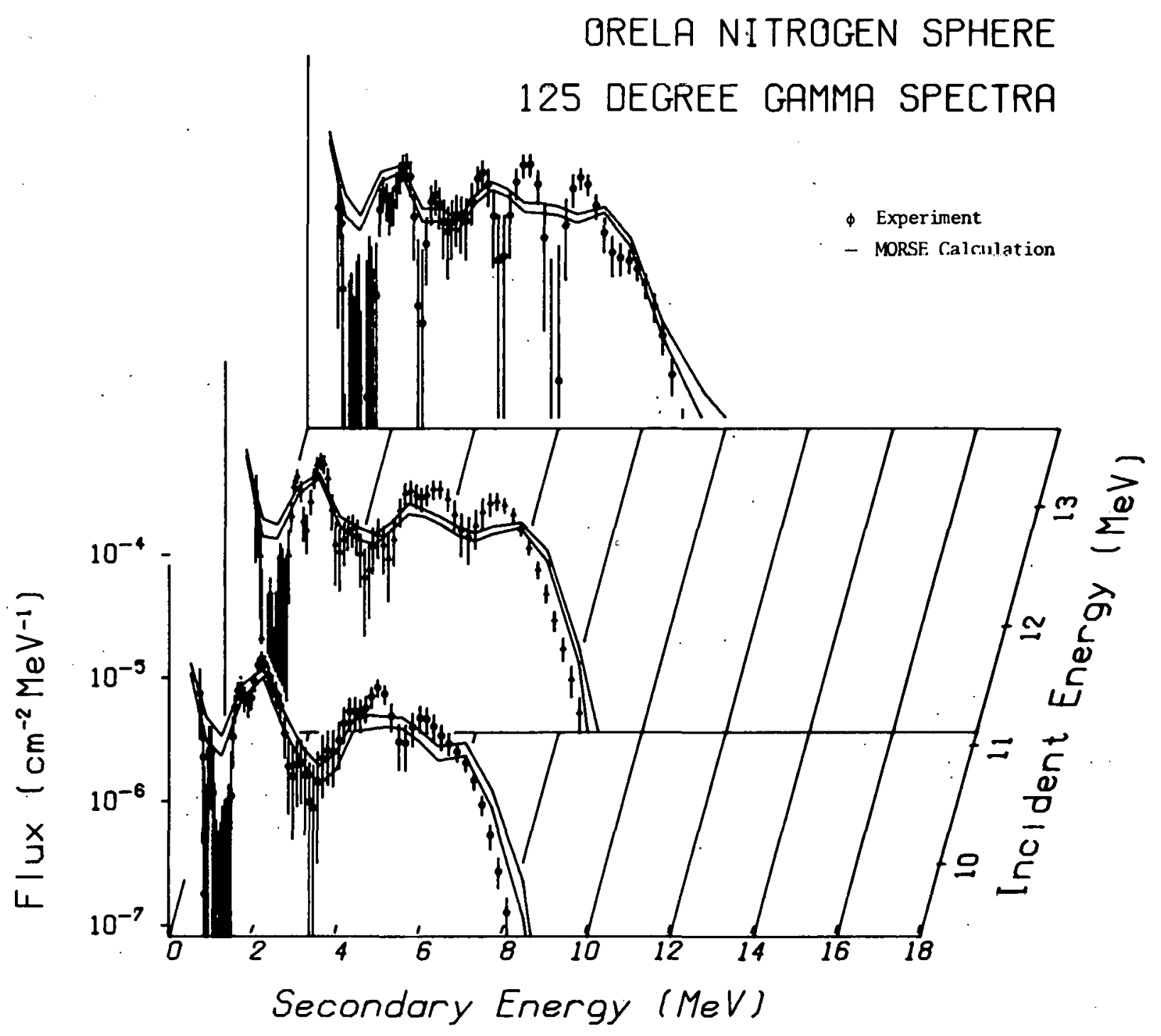

Fig. 44. ORNL Sphere Secondary Gamma-Ray Spectra at 125 deg Compared wi.th Calculatione Üsing ENDF/B-IV Niliugen Data. 
THIS PAGE

\section{WAS INTENTIONALLY \\ LEFT BLANK}


ORNL/TM-5220

\section{Internal Distribution}

1. L. S. Abbott

2. R. G. Alsmiller, Jr.

3. D. E. Bartine

4. C. E. Clifford

5-9. S. N. Cramer

10. J. K. Dickens

11. C. Y. Fu

12. H. Goldstein (consultant)

13. W. E. Kinney

14. D. C. Larson

15. T. A. Love

16. R. E. Maerker

17. F. C. Maiens chein

18. G. L. Morgan

19. F. R. Mynatt

20-24. E. M. Oblow

25. R. W. Peelle

26. F. G. Perey
27. R. W. Roussin

28. M. L. Tobias

29. C. R. Weisbin

30. A. Zucker

31. P. F. Fox (consultant).

32. W. W. Havens, Jr. ' (consultant)

33. A. F. Henry (consultant)

34. R. E. Uhrig (consultant)

35-36. Central Research Library

37. ORNL Y-12 Technical Library Document Reference section

38. Laboratory Records Department

39. Laboratory Records ORNL RC

40. ORNL Patent Office

41-42. Radiation Shielding Information Center

\section{External Distribution}

43. USERDA Oak Ridge Operations, Research \& Technical Support Division, P. O. Box E, Oak Ridge, TN. 37830: Director

44-70. Technical Information Center

71. Research and Technical Support Division

72-142. Given special NPD DNA distribution 